\title{
CLÚSTER DEL SECTOR DEL CUERO, CALZADO Y MARROQUINERÍA EN BOGOTÁ
}

\author{
YERALDIN BERNAL GONZALEZ \\ MICHAEL STIWAR QUEVEDO CAMACHO
}

UNIVERSIDAD SANTO TOMÁS

FACULTAD DE ADMINISTRACIÓN DE EMPRESAS

ADMINISTRACIÓN DE EMPREAS

BOGOTÁ D.C

2017 


\section{Contenido}

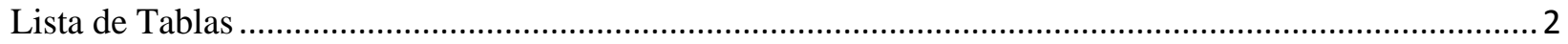

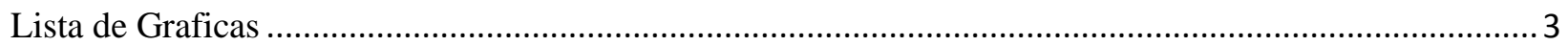

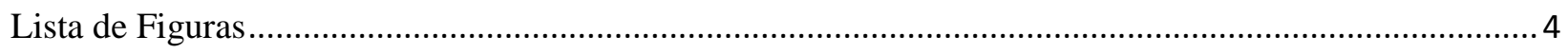

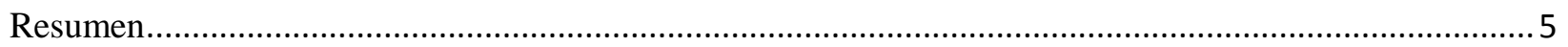

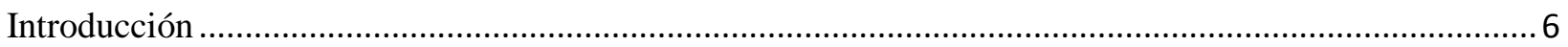

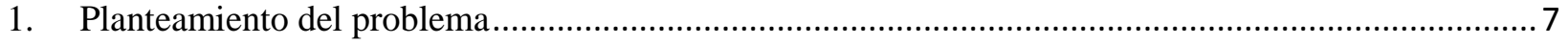

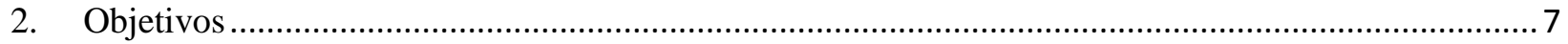

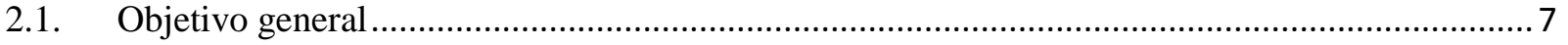

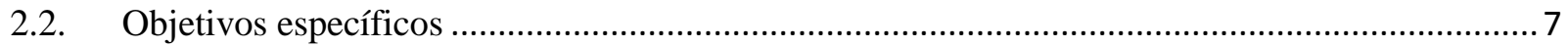

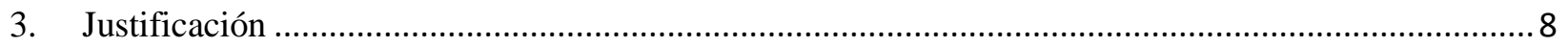

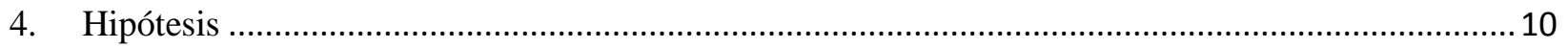

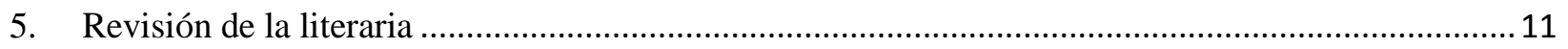

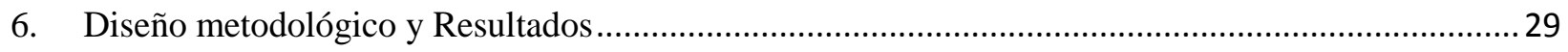

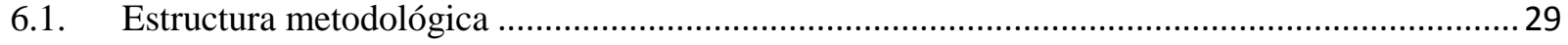

6.2. Muestra de la investigación..................................................................................................... 31

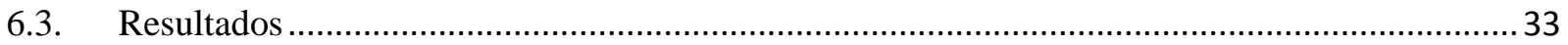

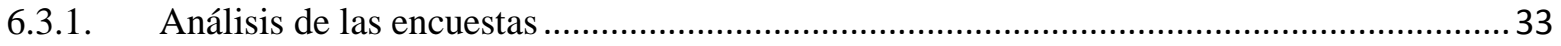

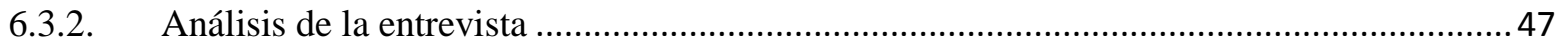

6.3.3. Análisis de los resultados ........................................................................................ 48

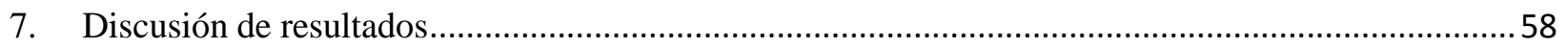

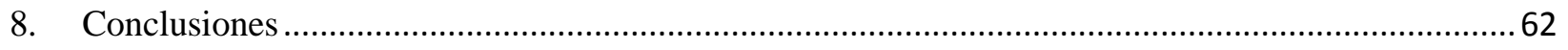

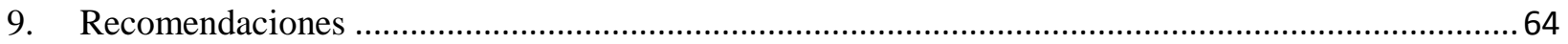

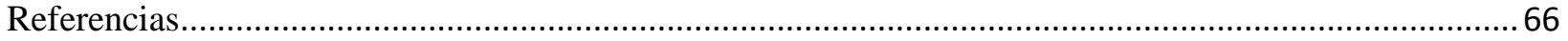

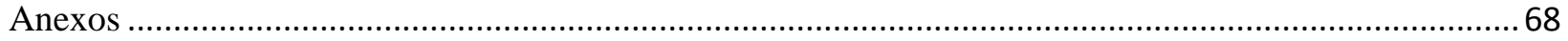

Anexo No. 1 - Entrevista a Doctor Juan Diego Cardona Echeverry …....................................................68

Anexo No. 2 - Modelo de la Encuesta Aplicada ...................................................................................... 72 


\section{Lista de Tablas}

Tabla 1. Elaboración propia - Relación de las empresas productoras encuestadas................................... 33

Tabla 2 Tabulación de Pregunta No 1 - ¿La empresa ha asistido a una capacitación sobre clúster?...........36

Tabla 3. Tabulación de Pregunta No 2 - ¿Ha sido útil para la empresa participar del clúster del sector del

Cuero, Calzado y Marroquinería?

Tabla 4. Tabulación de Pregunta No 3 - ¿La empresa ha recibido asesoría de alguna entidad de apoyo que pertenezca al clúster del sector del Cuero, Calzado y Marroquinería?

Tabla 5. Tabulación de Pregunta No 4 - ¿Cómo la empresa conoció el clúster del sector del Cuero,

Calzado y Marroquinería?.

Tabla 6. Tabulación de Pregunta No 5 - Califique el clúster del sector del Cuero, Calzado y Marroquinería en Bogotá

Tabla 7. Tabulación de Pregunta No 6 - ¿Con que tipo de empresas ha tenido mayor relación en clúster del sector del cuero, calzado y marroquinería?

Tabla 8. Tabulación de Pregunta No 7 - ¿Qué beneficio ha obtenido la empresa con el clúster del sector del Cuero, Calzado y Marroquinería?

Tabla 9. Tabulación de Pregunta No 8 - ¿Que lo llevo a integrarse al clúster del sector del Cuero, Calzado y Marroquinería?

Tabla 10. Comparación porcentual de las dificultades empresariales antes de pertenecer al clúster vs los beneficios obtenidos al ser integrante del clúster. 


\section{Lista de Graficas}

Grafica 1. Asistencia de empresas del clúster a capacitación sobre clúster ............................................36

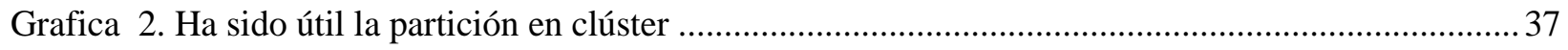

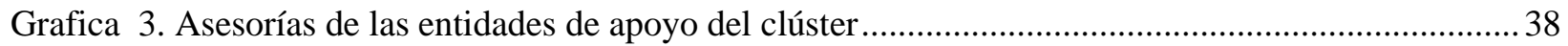

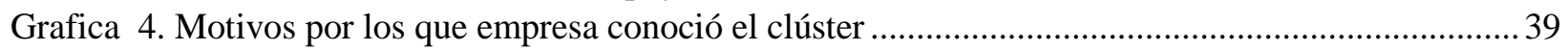

Grafica 5. Calificación del clúster del sector del cuero, calzado y marroquinería.................................... 41

Grafica 6. Tipos de empresa con los que ha tenido relación en el clúster ................................................42

Grafica 7. Beneficio obtenido de la empresa en el clúster ................................................................ 44

Grafica 8. Motivos de integración de las empresas al clúster del sector del cuero, calzado y

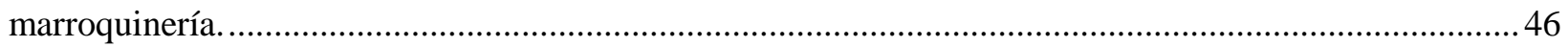

Grafica 9. Comparación grafica de las dificultades empresariales antes de pertenecer al clúster vs los beneficios obtenidos al ser integrante del clúster..............................................................................52

Grafica 10. Tiempo de permanencia de la muestra empresarial que está vinculada al clúster del sector del

cuero, calzado y marroquinería en Bogotá..........................................................................................53

Grafica 11. Comparación de los beneficios recibidos por las empresas productoras del sector del cuero, calzado y marroquinería, teniendo en cuenta el tiempo de pertenencia..................................................54 


\section{Lista de Figuras}

Figura 1. Los determinantes de la ventaja competitiva nacional............................................................. 19 


\section{Resumen}

Este trabajo de grado consiste en identificar los beneficios de un clúster en las empresas productoras del sector del cuero, calzado y marroquinería en Bogotá.

Para ello se realizó una revisión de literatura que es importante para la investigación, esta desarrolla toda la teoría de lo que es el clúster, su fundamento en el diamante de Michael Porter y como este ha aportado al crecimiento de diferentes sectores productivos de una economía, esto con el fin de obtener una comprensión más clara de los puntos a tratar y lograr el cumplimiento de los objetivos establecidos.

Se aplicó una encuesta de 8 preguntas a 30 empresas productoras equivalentes al $30 \%$ del total que actualmente integran el Clúster del cuero, calzado y marroquinería en Bogotá, para esto se contó con el apoyo de la Cámara de Comercio de Bogotá quien brindó un espacio para aclarar y proveer los contactos para el desarrollo de este trabajo de grado.

De esta recolección de información se hizo el análisis de datos para obtener los resultados finales para establecer los beneficios y la importancia del clúster en las empresas productoras del sector del cuero, calzado y marroquinería en Bogotá y como este ha impactado al crecimiento del sector.

Finalmente, con este trabajo de grado se realizaron recomendaciones de mejora y la difusión de información acerca de las entidades del gobierno y universidades que apoyan e impulsan crecimiento organizacional de los sectores productivos del país. 


\section{Introducción}

Las organizaciones hoy en día están en la búsqueda de nuevas alternativas que le permitan ser más competitivas y rentables en un mercado creciente, no es un secreto la situación económica que atraviesa el país y como esto impacta el mercado nacional. Esto conlleva a los gerentes una preocupación por implementar herramientas que le permitan el control y sostenimiento de la organización.

El desarrollo de este trabajo de grado está enfocado a las empresas productoras que integran el clúster del sector del cuero, calzado y marroquinería de Bogotá, en el cual se pretende identificar los beneficios que puede llegar a obtener las empresas una vez estén integradas al clúster, y como pueden influenciar para generar cambios internos para el crecimiento organizacional. Es importante resaltar el apoyo de la Cámara de Comercio de Bogotá, quienes actualmente lideran la iniciativa clúster del sector, ya que brindaron información para realizar el contacto con las empresas y lograr la recolección de información, para contrastar la situación de las empresas antes de integrar el clúster frente a su situación actual.

Para esta investigación se trabajaron dos enfoques de investigación: descriptivo y exploratorio, los cuales permiten dar respuesta a la hipótesis planteada y conducirnos al cumplimiento de objetivos de este trabajo de grado.

Sin embargo, a lo largo de esta investigación se encontraron vacíos dentro del clúster, lo cual aporto al crecimiento y desarrollo de este trabajo, para hacer recomendaciones de mejora que permitan el fortalecimiento del trabajo colaborativo del clúster en pro de desarrollar empresas más competitivas y rentables.

Con los resultados de esta investigación se pretende resaltar la importancia de la participación de las empresas productoras en el clúster del sector del cuero, calzado y marroquinería, a su vez evidenciar cuales son los beneficios obtenidos a través de los años de permanencia en el mismo. 


\section{Clúster del sector del cuero, calzado y marroquinería en Bogotá}

\section{Planteamiento del problema}

¿Cuáles son beneficios que obtienen las empresas productoras que integran el clúster del sector del cuero, calzado y marroquinería en Bogotá?

\section{Objetivos}

\subsection{Objetivo general}

Identificar los beneficios del clúster, a través de la consulta a empresas productoras y entidades de apoyo que integran el clúster el sector del cuero, calzado y marroquinería en Bogotá, para resaltar la importancia de integrar un clúster.

\subsection{Objetivos específicos}

$\checkmark$ Identificar los beneficios de las empresas productoras que integran el clúster del sector del cuero, calzado y marroquinería en Bogotá, para evidenciar la situación de las empresas antes de integrar el clúster.

$\checkmark$ Contrastar los beneficios obtenidos por las empresas que integran el clúster del sector del cuero, calzado y marroquinería en Bogotá, frente a las necesidades organizacionales antes de integrar el clúster, para demostrar el indicador de cumplimiento del clúster.

$\checkmark$ Comparar las empresas productoras que integran el clúster del sector del cuero, calzado y marroquinería en Bogotá a través de los años de participación en el clúster, para sugerir mejoras al clúster.

$\checkmark$ Analizar la información recopilada a las empresas productoras y entidades de apoyo que integran el clúster del sector del cuero, calzado y marroquinería en Bogotá, para resaltar la importancia de integrar un clúster. 


\section{Justificación}

La motivación para el desarrollo de este trabajo de grado surge del interés de conocer cuáles son los beneficios de una empresa al ser integrante de un clúster, para este caso nos enfocamos en las empresas productoras del sector del cuero, calzado y marroquinería en Bogotá, quienes desde "2007 se vieron afectados por la importación de productos principalmente provenientes de China, y en el 2012 atravesaron su peor crisis debido al incremento en las importaciones de 290 millones de dólares a 636 millones de dólares, donde 6 de cada 10 productos del sector provenían del extranjero" (Botero, 2015).

Uno de los planes de acción para fortalecer el sector fue la creación del clúster en el año 2012, el cual se creó con el acompañamiento de la Cámara de Comercio de Bogotá, dado que en esta misma época se empezó a trabajar en su proyecto de Iniciativas Clúster para este sector. Teniendo en cuenta que un clúster es una herramienta que sirve para fortalecer el sector económico al cual pertenecen las empresas a través de su aglomeración para trabajar de forma conjunta con el fin de ser más competitivos, suplir sus necesidades e impulsar el crecimiento económico y el desarrollo de sus cadenas de valor.

De acuerdo a lo anterior para el desarrollo de este trabajo de grado se emplearon encuestas a las empresas productoras que integran el clúster del calzado, cuero y marroquinería de Bogotá, para conocer más acerca de las diversas situaciones por las que han atravesado, y lograr evidenciar y contrastar los beneficios de dicha iniciativa. Adicional se contó con la colaboración de la Cámara de Comercio de Bogotá, quienes lideran la iniciativa clúster del sector.

Por lo tanto, en esta investigación se propone identificar y dar a conocer los beneficios que impulsa esta herramienta, y al tiempo establecer sugerencias de mejora que ayuden a las empresas productoras que integran el clúster del sector del cuero, calzado y marroquinería en Bogotá. 
Con este trabajo de grado se pretende aportar y difundir información a los estudiantes y futuros profesionales de administración de empresas de la Universidad Santo Tomas, acerca de las nuevas herramientas promovidas y apoyadas por las entidades del gobierno e instituciones educativas privadas fomentando el emprendimiento, la capacitación del recurso humano y la generación de nuevos empleos.

No obstante dejar constancia del desarrollo de las empresas promoviendo la responsabilidad social y el cuidado del medio ambiente, ya que el sector del cuero, calzado y marroquinería es una industria que afecta los recursos hídricos en la ciudad de Bogotá, y luego de la participación en esta iniciativa han potencializado sus procesos de producción con recursos de última tecnología impactando en la calidad de sus productos y disminuyendo la contaminación ambiental.

Finalmente, con este trabajo de grado pretendemos resaltar la importancia del clúster del sector del cuero, calzado y marroquinería de Bogotá, basado en el trabajo colaborativo entre empresas de un mismo sector, en pro de tomar mejores decisiones que permitan mejorar su competitividad en el mercado y suplir sus necesidades de negocio. 


\section{Hipótesis}

Ser parte de un clúster brinda una perspectiva nueva y diferente para las empresas, esto en pro de establecer sinergia entre las empresas que integran el clúster del sector del cuero, calzado y marroquinería en Bogotá, lo que permite una mejor toma de decisiones, romper barreras entre empresas grandes o pequeñas, encontrar solución a los problemas comunes e impulsar el desarrollo de nuevas prácticas empresariales que busquen rentabilidad y la mejora de las condiciones sociales, económicas o ambientales de los integrantes del clúster.

De acuerdo a lo anterior desarrollaremos este trabajo de grado sobre la siguiente hipótesis:

"Los beneficios del clúster han permitido el desarrollo de las empresas productoras de cuero, calzado y marroquinería de Bogotá” 


\section{Revisión de la literaria}

\section{Antecedentes históricos sobre el clúster}

El clúster fue un concepto propuesto por Michael Porter a principios de los años noventa, el cual lo define como "Un clúster es un grupo geográficamente denso de empresas e instituciones conexas, pertenecientes a un campo concreto, unidas por rasgos comunes y complementarias entre sí” (Porter, 2009, p.265). Pero a lo largo de la historia más autores han hablado sobre las concentraciones industriales, y uno de ellos fue el economista Alfred Marshall en el siglo XIX como citó (Reina, 2015) en su artículo "Bondades de la estrategia clúster para el desarrollo regional":

"Todas las unidades productivas debían concentrarse en un solo lugar; sin embargo, también planteó la posibilidad de aglutinar varias fábricas de menor tamaño en un espacio geográfico determinado, para repartir así algunas actividades de un mismo proceso productivo. Este principio fue concebido para operaciones industriales con elevados volúmenes de producción. Llevando de esta forma la división del trabajo, más allá de la integración vertical endógena, a la operación especializada de varias compañías que se aglutinan en un espacio determinado y llevan a cabo operaciones que, en últimas, hacen parte de un fin mayor. Esta nueva forma de operar recibió el nombre de Aglomeraciones o Distritos Industriales” (2015)

Cuando Marshall planteo los distritos industriales se puede analizar que empezaron a existir las redes empresariales geográficamente, lo cual contribuye a crear estrategias de expansión con la ayuda de las fabricas pequeñas para realizar procesos que agilizaban la producción, esto contribuye a disminución de costos para las industrias grandes y fomentaban el trabajo en la sociedad, y esta teoría fue apoyada con la teoría del distrito de Becattin que se desarrolló en Italia con la subcontratación de las empresas pequeñas con los procesos operativos que realizaban las grandes industrias y se logró una especialización. 
El economista italiano Florentino Giacomo Becattin con su Teoría del Distrito, él comenta que en los años sesenta del siglo XX algunos economistas italianos identificaron que las pequeñas empresas están aglomeradas y se presentan técnicamente preparadas para el trabajo que realizan, en un nivel parecido al de las grandes empresas, por lo tanto (Becattini, 2002) da a conocer que:

"Las nuevas empresas no nacen en el interior de las ciudades industriales, y en casi todos los sectores se extienden territorialmente en una amplia área intermedia entre las regiones del desarrollo capitalista clásico y las de la economía deprimida del Sur de Italia, para concentrarse en áreas relativamente restringidas que, a menudo, la teoría corriente de la localización industrial no considera atractivas para la inversión" (p.18)

Este fenómeno lo explica (Becattini, 2002) con "las condiciones locales de oferta y las condiciones generales de demanda", dado que las empresas grandes, que no pueden seguir produciendo empiezan a subcontratar a pequeñas empresas ubicadas cerca de sus fábricas que se van especializando en partes del proceso. Por este motivo (Becattini, 2002) dice:

"Si se crea una adecuada atmósfera industrial, hecha de conocimientos técnicos como de moralidad comercial, el paso desde un predominio de valores jerárquicos entre secciones, como se produce en el interior de una gran empresa, al predominio de relaciones de intercambio (aunque sea con elementos de desigualdad que, de todas formas, se pueden atenuar hasta desaparecer con el paso del tiempo) entre empresas autónomas, crea un diferencial positivo de confianza entre los agentes, que reduce el costo global de la producción del distrito considerado en su conjunto" (p. 19)

Se puede decir que los clústers se encuentran en distintas regiones del mundo desde hace muchos años, con ejemplos tan característicos como los distritos industriales 
de Italia o en Inglaterra con la revolución industrial y como desde esta época se evidencian los beneficios de los clústers.

En 1991 el economista estadunidense Paul Krugman donde presenta su "Teoría Geográfica Económica” esta se enfoca en los costos de transporte, la infraestructura específica y explica por qué es necesario contar con personal, proveedores e instituciones de calidad para fortalecer la competitividad donde enfatiza mejorar aspectos como las economías de aglomeración y el impacto geográfico. Adicional, explica que las economías de aglomeración buscan proximidad geográfica a un mercado que permita reducir costos, ventajas de tecnológicas, cultura empresarial, fortalecer una relación geográfica más cercana entre productores y proveedores. (Andrade, 2016) Comparte la importancia de teoría de Krugman y que actualmente complementa la herramienta clúster:

"Es importante ya que introduce nuevos instrumentos para explicar "la localización económica en el espacio", particularmente en lo que se refiere a la simulación numérica y a modelos de competencia imperfecta para analizar el comercio internacional, pero en donde no solo se toma en cuenta los planteamientos importantes como las ideas de expansión del mercado, la división y especialización del trabajo y el concepto de economías externas para fomentar el crecimiento económico, sino también ahora aspectos geográficos importantes como la distancia, los costos de transporte, los rendimientos crecientes, para justificar la desigual de la distribución, nacional y mundial, de la actividad económica y la incorporación de externalidades espaciales y las economías de aglomeración; para explicar los procesos de acumulación de riqueza en los lugares inicialmente favorecidos por la localización de un conjunto de actividades económicas y la importancia de las multinacionales" (2016)

Después de conocer la descripción de las diferentes teorías que contribuyeron con el desarrollo de los clústers, se pueden empezar a evidenciar algunos beneficios que se obtienen de implementar alguna de estas teorías, como por ejemplo la integración con sus 
competidores y proveedores para promover el desarrollo empresarial, disminución en costos, expansión en el mercado e innovación, por estas razones se puede decir que los clústers es una estrategia de crecimiento y actualmente muchos sectores se interesan en su constitución como lo hizo el sector del cuero, calzado y marroquinería en Bogotá y que actualmente trabajan en él para su fortalecimiento empresarial.

\section{¿Qué es un clúster?}

Para definir que es un clúster se hace referencia a las diferentes definiciones que han surgido a lo largo de los años por diferentes autores:

"Un clúster es un grupo de empresas interconectadas e instituciones relacionadas en un determinado campo, que se encuentran próximas geográficamente, y que están vinculadas a través de elementos comunes y complementariedades." (Porter, 1998)

"El concepto más general de clúster sugiere menos estricto: una tendencia de las empresas dedicadas a actividades similares a localizarse, aunque sin tener una presencia particularmente importante en un área geográfica." (Crouch \& Farell, 2001)

"Un clúster es utilizado de forma muy sencilla para representar concentraciones de empresas que son capaces de producir sinergias debido a su proximidad geográfica y a la existencia de interdependencias entre ellas, a pesar de que su peso en el empleo total no sea preponderante ni incluso relevante." (Rosenfeld, 1997)

"Los clústers económicos no sólo tienen que ver con sectores e instituciones de apoyo, sino que tienen que ver con ellos tanto en cuanto sean más competitivos debido a las relaciones que establecen entre ellos." (Feser, 1998) 
"Definimos un clúster innovador como un amplio número de empresas industriales o de servicios que tienen un alto nivel de colaboración, habitualmente a través de una supply chain, y operando bajo similares condiciones de mercado." (Simmie \& Sennett, 2002)

"Losclúster pueden ser caracterizados como redes de empresas muy interdependientes (que incluyen proveedores especializados) relacionadas entre sí a través de una cadena de producción de valor.” (Roelandt \& Den Hertog , 1999)

Después de estas múltiples definiciones cabe resaltar que el concepto más sobresaliente y real es el de Michael Porter, ya que es considerado el padre de competitividad. Aunque es importante resaltar que las demás definiciones han generado interés para la creación de clúster, dado que un clúster es herramienta para desarrollar estrategias de fortalecimiento empresarial para generar beneficios para sus integrantes.

\section{Modelo Clúster, competitividad y valor compartido}

El concepto de los clúster surge a principios de la década de los noventa por Michael Porter como una manera de explicar la ventaja competitiva que se tiene por medio de la localización, y si unen las empresas pueden alcanzar mayores niveles de crecimiento y desarrollo económico, por esta razón las asociaciones clúster son una aglomeración que concentra empresas de un específico sector industrial, y se asocian con instituciones académicas y gubernamentales con el fin de buscar nuevas formas de ser más competitivos. A esta idea le apunta el clúster del sector del cuero, calzado y marroquinería, dado que a las diferentes problemáticas que ha enfrentado en mercado presenta un nivel bajo de competitividad no solo a nivel nacional sino internacional.

Partiendo de este concepto se empezó hablar de las iniciativas de asociación de las empresas del mismo sector con el fin de impulsar el crecimiento económico del sector. 
Por esta razón un clúster busca que por medio de sus alianzas se genere ventajas competitivas, (Porter, Ser Competitivo, 2009) en su obra dice que los clústers afectan la competencia en tres aspectos:

$\checkmark$ Incrementa la productividad.

$\checkmark$ Incrementa su capacidad de innovar.

$\checkmark$ Estimula la creación de empresa.

Por lo tanto, estas variables hacen exitoso al clúster, por esta razón la productividad, innovación y creación de empresa son un objetivo para el clúster del sector del cuero, calzado y marroquinería ya que se van a convertir en beneficios.

La productividad en un clúster busca acceso a recursos materiales y humanos especializados, pero no siempre todos los recursos se pueden encontrar en el mismo sector por esta razón cuando los clústers están muy desarrollados se vuelven aliados con otros clústers con el fin de intercambiar material, información o tener complementariedad.

La innovación en un clúster es cuando las empresas que pertenecen a ese suelen ser más perceptivos a identificar las necesidades o las nuevas oportunidades de negocio (Porter, 2009) dice:

"La participación de un clúster también ofrece ventajas a la hora de percibir nuevas posibilidades en tecnología, producción o comercialización. Los participantes se enteran enseguida de las tecnologías que están surgiendo, de la disponibilidad de nuevos componentes y maquinas o de los nuevos sistemas de venta y servicio, gracias a su relación permanente con otras entidades del clúster, y cuentan además con la posibilidad de visitar las instalaciones de otras empresas y de establecer contactos personales" (p.292) 
Cuando una empresa hace parte de un clúster suele enterarse más pronto de las necesidades de los clientes, pero al tiempo de la tecnología que soluciona esa necesidad. Adicionalmente, si se unen la productividad e innovación se logra reducción de costos, fluye la información y se alcanza una respuesta más rápida de las instituciones gubernamentales y académicas sobre las necesidades del clúster.

La formación de empresas a través de los clústers, es una gran oportunidad ya que las barreras para ingresar al mercado son menores, pueden contar con facilidades para obtener los recursos financieros, infraestructura, humano o materia prima. También fomenta el crecimiento del clúster en el tiempo y sirve como ejemplo de motivación para la creación de empresas.

Por lo tanto, la formación de clústers funcionan como una herramienta generadora de estrategias de competitividad, lo cual busca es ofrecer ventajas competitivas para sus integrantes, y esto depende de la interacción y comunicación que halla entre los integrantes para que se genere la colaboración en proyectos específicos. Michael Porter lo dice en su obra Ser Competitivo:

La teoría de clúster tiene un puente entre la teoría de las redes y competencia. Por lo tanto, un clúster es una forma de organizar las redes en una zona geográfica y en la cual la proximidad de las empresas e instituciones asegura de cierta forma a la comunidad a incrementar la frecuencia y el efecto de las relaciones (Porter, 2009, p. 298).

Se puede determinar que el objetivo de estas iniciativas es articular a las empresas a buscar proyectos de impacto que puedan captar nuevos mercados, lo cual no significa captar clientes, también proveedores o canales distribución, ya que un clúster lo que genera es integración para promover competencia y esta debe ser "dinámica y se basa en la innovación y en la búsqueda de diferencias estratégicas” (Porter, 2009, p. 278), por lo tanto las iniciativas clúster deben ser dinámicas y estar en búsqueda permanente de nuevas ideas con el fin de generar innovación y valor compartido el cual es definido 
(Kramer \& Porter, 2011) “como las políticas y prácticas operativas que incrementan la competitividad de una compañía desarrollando simultáneamente condiciones económicas y sociales en las comunidades donde las empresas tienen el asiento de sus negocio”, cuando mencionamos "compartido" se hace referencia que todo debe ser equitativo por ello se crean políticas y prácticas que todos deben cumplir porque lo que se busca es un gana - gana con el fin de que el sector pueda crear estrategias, para lograr las tres oportunidades del valor compartido que nos comparte (Kramer \& Porter, 2011):

$\checkmark$ Reinvención de productos y mercados

$\checkmark$ Redefinición de la productividad en la cadena de valor

$\checkmark$ Desarrollo de clúster locales de empresas

Estas tres oportunidades que brinda el valor compartido buscan que se identifiquen las necesidades de la sociedad y basado en ellas generen productos tangibles o intangibles que satisfagan las necesidades, por otra parte, se debe buscar el progreso social y que las compañías interactúen entre sí y su entorno porque un clúster es la unión de empresas, instituciones académicas, instituciones gubernamentales, organizaciones de comercio para generar competencia justa y transparente.

(Porter, 1991) dice que para crear un ambiente en que las empresas aprendan a competir debe tener claros los 4 determinantes de la ventaja competitiva que se muestran en la figura No. 1 y a continuación los describimos:

$\checkmark$ “Condiciones de los factores: Situación de la nación en cuanto a los factores de producción, tales como la mano de obra especializada o la infraestructura, necesarios para competir en un sector determinado.

$\checkmark$ Condiciones de la demanda: Naturaleza de la demanda del producto o servicio del sector en cuestión en el mercado interior. 
Sectores afines y auxiliares: Presencia o ausencia de la nación de sectores proveedores y afines que sean internacionalmente competitivos.

$\checkmark$ Estrategia, estructura y rivalidad de las empresas: Las condiciones en la nación que rige el modo con que las empresas se crean, organizan y gestionan, así como la naturaleza de la competencia interna". (p.174)

Figura 1. Los determinantes de la ventaja competitiva nacional.

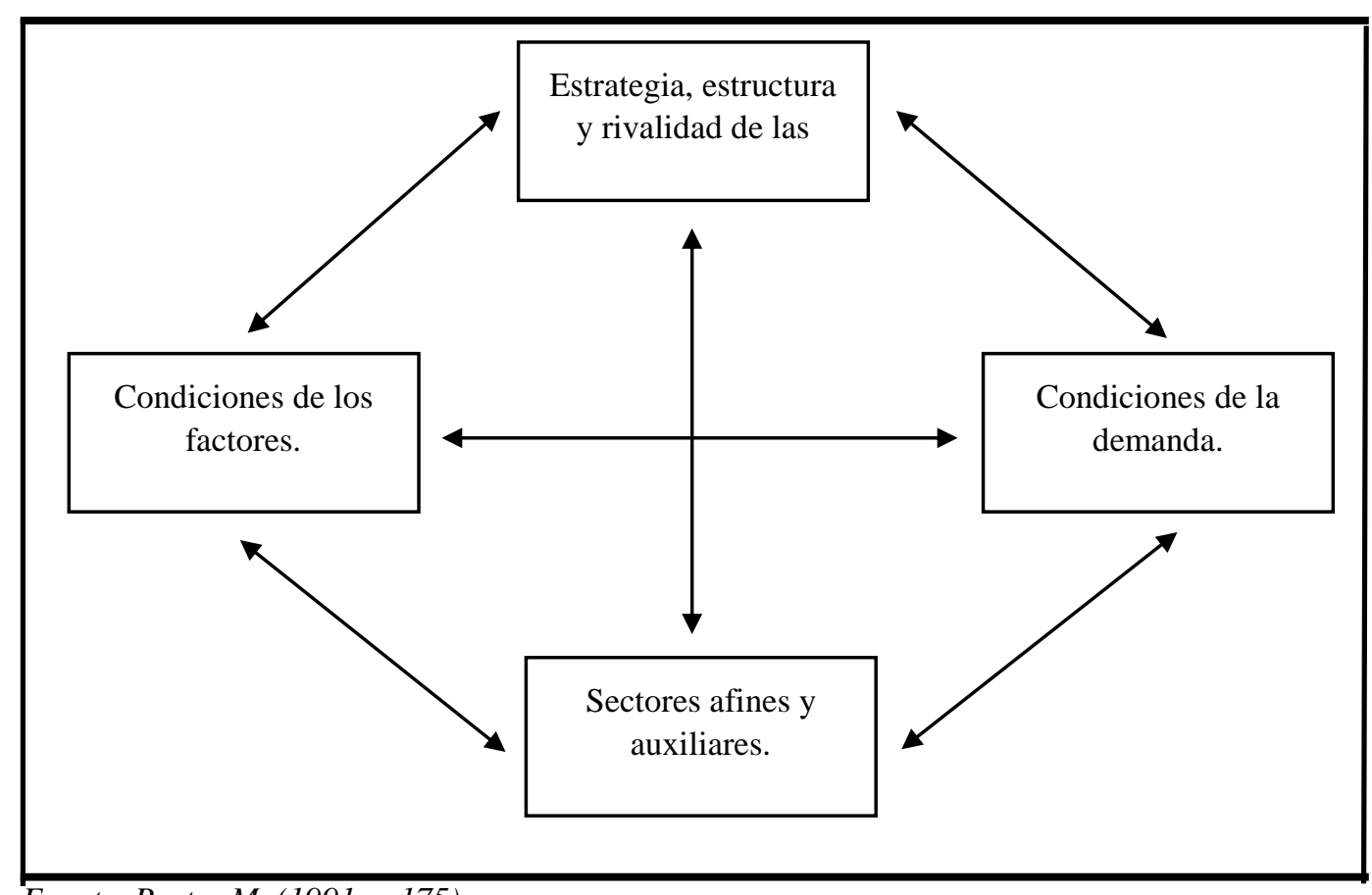

Fuente. Porter M. (1991, p.175)

Por cierto, en el análisis de Porter los clústers se dan tanto en torno a los recursos naturales, así como en torno a actividades basadas en el aprendizaje y conocimiento. Por estas razones el sector del cuero, calzado y marroquinería en el momento de iniciar el clústers realizo un análisis de las falencias del sector para de esta misma forma establecer sus objetivos a cumplir en esta unión empresarial.

Todas las hipótesis anteriormente mencionadas acerca de la formación de clúster tienen en común la noción de que la competitividad de cada empresa es potenciada por la competitividad del conjunto de empresas y actividades que conforman el clúster al cual 
pertenecen. En efecto, esa mayor competitividad deriva de importantes economías de aglomeración, desarrollo tecnológico e innovaciones que surgen de la intensa y repetida interacción entre las empresas y actividades que conforman el clúster. Las distintas empresas y actividades que constituyen el clúster se refuerzan mutuamente. La información fluye, los costos de transacción son menores, nuevas oportunidades son percibidas antes y las innovaciones se difunden rápidamente a lo largo de la red. Hay fuerte competencia en precio, calidad y variedad. Ésta da lugar a nuevos negocios, fortalece la rivalidad entre empresas y contribuye a mantener la diversidad.

Además, facilita la cooperación activa y consciente de sus miembros en pro de una mayor eficiencia productiva y la colaboración entre empresas para abrir nuevos mercados, desarrollar nuevos productos. Este ha sido uno de los grandes logros del clúster del sector del cuero, calzado y marroquinería ya que han logrado apertura de nuevos mercados e innovación como uno de los grandes beneficios la implementación de clúster.

\section{Beneficios del clúster}

Un clúster busca mejorar la competitividad y formar cadenas productivas, esto con el fin de facilitar ventajas competitivas y alcanzar los beneficios que ofrece esta herramienta. La clave de un clúster es la comunicación a través de reuniones de los diferentes actores para dar a conocer las diferentes problemáticas y formular las posibles soluciones.

Estas posibles soluciones son las que llevan alcanzar los beneficios de los integrantes del clúster como:

$\checkmark$ Sobrevivir a la globalización

$\checkmark$ Innovación

$\checkmark$ Nuevos Mercados

$\checkmark$ Procesos de distribución y producción 
$\checkmark$ Disminución de costos

$\checkmark$ Aumento de ventas

$\checkmark$ Procesos de Calidad

Hay beneficios que se han establecido por los diferentes proyectos clúster, que han alcanzado un impacto mayor y que pueden contribuir a una integración en el mercado más amplia la (Camara de Comercio de Madellin, 2015) dice que estos pueden ser algunos de estos beneficios:

$\checkmark$ Acceso a información y conocimiento especializado, experiencias y buenas prácticas.

$\checkmark$ Participación en proyectos estratégicos.

$\checkmark$ Participación en redes colaborativas que redundan en proyectos y acciones conjuntas de impacto para los negocios.

$\checkmark$ Establecimiento de relaciones con pares en los ámbitos nacional e internacional para estimular la transferencia de conocimiento, la generación de oportunidades de negocios o el desarrollo de proyectos estratégicos conjuntos.

$\checkmark$ Fortalecimiento empresarial y mejoramiento de la posición competitiva en los mercados.

Estos beneficios son los que buscan obtener el clúster del sector del cuero, calzado y marroquinería en Bogotá, por medio de este trabajo de grado se analizara cuales fueron alcanzados y los que aún no, para realizar recomendaciones para que sean logrados.

\section{Sector del cuero, calzado y marroquinería}

El sector del cuero, calzado y marroquinería en Colombia se considera uno solo, dado tiene una misma cadena productiva como lo indica (Departamento Nacional de Planeación, 2004) "la cadena productiva del cuero tiene cuatro actividades que son: la producción de cuero crudo, el procesamiento de la piel en la actividad de curtiembre, la producción de productos de marroquinería y la industria del calzado", por esta razón estas 
cuatros actividades siempre se unifican en el mismo sector, dado que sus necesidades son muy similares y se complementan entre sí para su desarrollo económico.

Por lo tanto, es importante resaltar que todo este sector gira alrededor el cuero y transformación de este se deprenden cuatro actividades que pueden convertirse en subsectores los cuales se definen como lo menciona el informe de (Departamento Nacional de Planeación, 2004):

Producción de cuero crudo: La obtención del cuero crudo se da después del sacrificio de los animales. Para la producción de la curtiembre, la principal materia prima es la piel cruda de origen bovino.

$\checkmark$ Curtiembre: El curtido es el proceso de sometimiento de la piel a acciones físico químicas para convertirla en un material duradero. Esta parte del proceso de producción comprende tres fases: la ribera, el curtido, el teñido y acabado.

Marroquinería y talabartería: Es la parte del proceso productivo se obtienen las manufacturas de cuero y prendas de vestir de este material. Se compone de cinco pasos básicamente: diseño, modelo, cortado, guarnecido, terminado y empaque.

$\checkmark$ Calzado: Una característica importante del proceso de producción del calzado es que requiere insumos diferentes al cuero, como son los textiles, el caucho y el plástico. El proceso de fabricación del calzado se inicia con la fabricación de suelas, luego viene el cortado de la pieza previamente patronada $\mathrm{y}$, posteriormente, el proceso de guarnecido.

Por ser una sola cadena productiva se considera un solo sector económico, por esta razón las diferentes asociaciones que existen para regular o apoyar este sector reúnen las cuatro actividades. Teniendo en cuenta esta cadena productiva, el clúster de este sector esta unificado de la misma forma, dado que si se divide por actividades no se complementa para buscar la solución de las falencias del sector. 


\section{Crisis del sector del cuero, calzado y marroquinería}

La llegada del producto extranjero específicamente el chino afecto considerablemente el mercado del sector del cuero, calzado y marroquinería, dado que este país realizaba exportaciones de producto terminado a precios muy bajos. En una entrevista realizada en el 2011 a Luis Gustavo Flórez el Presidente de la Asociación Colombiana de Industriales del Calzado, el Cuero y sus Manufacturas (Acicam) dijo:

"En el 2010 las exportaciones de cuero principalmente crudo a China crecieron 44\%. Al mismo tiempo, la disponibilidad de esta materia prima ha empezado a disminuir en el país, provocando un alza en los precios que llega hasta el 17\%. Nos preocupa enormemente porque nosotros tenemos una industria de curtiembre muy importante, pero no estamos exportando productos con valor agregado. Hoy el cuero sale directamente de los mataderos, se 'sala' para que no se pudra y se va para afuera. Y después a nosotros nos lo exporta China procesado (a precios que pueden ser hasta 12 veces superiores al que se lo vendemos)" (Flórez, La crisis del cuero, 2011)

Esta situación fue preocupante para el sector en general para Colombia, ya que muchas de las pymes del sector estaban quebrando, por esta razón a nivel nacional se toman acciones a nivel departamental; en el caso de las empresas de la ciudad de Bogotá con acompañamiento de la Cámara de Comercio de Bogotá se constituye el clúster del sector y ellos su iniciativa para trabajar conjuntamente y fomentar el crecimiento del sector.

A pesar de estos múltiples esfuerzos en una entrevista que brindo nuevamente el señor Luis Gustavo Flórez el Presidente de la Acicam manifiesta:

"Las condiciones de globalización de los mercados han incrementado las importaciones de calzado, el principal problema que enfrenta actualmente el país 
es el precio con el que ingresan este producto. Lo que resulta aún más preocupante es la deficiencia en los controles aduaneros" (Flórez, 2015)

Aunque el clúster del sector del cuero, calzado marroquinería trabaja activamente con el fin de mejorar esta situación el sector necesita más unificación en procesos y colectividad en el sector.

\section{Clúster en Colombia}

Colombia con el fin de fortalecer la economía del país creo el Programa de Rutas Competitivas y han logrado:

Desarrollar 36 iniciativas clúster en 18 departamentos en el país; iniciativas clúster que vienen trabajando con Comisiones Regionales de Competitividad en el marco de proyectos para su fortalecimiento; clúster que vienen fortaleciendo por su lado Cámaras de Comercio de varias ciudades, como Medellín, Cali, Barranquilla y Bogotá; y recientemente, las dinámicas locales para el desarrollo de los sectores del Programa de Transformación Productiva del Ministerio de Comercio, Industria y Turismo" (Red Cluster Colombia, 2016).

Estos proyectos han fortalecido la cooperación entre las empresas grandes y las pymes lo cual favorecido a la creación de estrategias de integración, promover la innovación e identificar nuevos mercados; todo esto con el fin de implementar políticas para mejorar la competitividad en el mercado ya que la economía cada día avanza a gran escala, por esta razón el desarrollo de las iniciativas clúster son de gran impacto en el país como lo expresa la (Red Cluster Colombia, 2016) en su mensaje de bienvenida:

"Las iniciativas clúster son una gran noticia para la competitividad de Colombia, dado que el proceso de transformación productiva, entendido como la mayor diversificación y sofisticación del aparato productivo que tanto necesita el país, se gesta principalmente desde el nivel local, en buena medida a través de esfuerzos por desarrollar clúster y apuestas productivas” (2016). 
El hecho de que estos proyectos se realicen en Colombia motivan a los empresarios, ya que una empresa para entrar al mercado, buscar alianzas entre otros retos que tienen que asumir es de gran complejidad. Estos proyectos fomentar el crecimiento y la creación de empresa, lo cual contribuye a que el país crezca para su desarrollo y al tiempo muestra los beneficios de esta estrategia de competitividad llamada clúster.

Iniciativas Clúster del sector del cuero, calzado y marroquinería en Bogotá.

La Cámara de Comercio de Bogotá apoya los proyectos donde se busque integrar cadenas productivas que generen valor compartido, por esta razón ellos sirven como soporte de las iniciativas clúster y su propósito es "facilitar a los empresarios que se conecten entre sí y propicien espacios con la academia y los gobiernos, que les permitan no solo complementarse, también mejorar la estrategia de sus negocios y el entorno del clima de inversión en Bogotá y en la región” (Camara de Comercio de Bogotá, 2014), este propósito muestra que las integraciones entre los competidores, proveedores, gobierno y la academia, surgen ideas que crean valor compartido que buscan el desarrollo, crecimiento y autosostenimiento. Finalmente, la Cámara de Comercio de Bogotá cuenta actualmente con 13 iniciativas clúster que son las siguientes:

\footnotetext{
$\checkmark$ Iniciativa Clúster de Prendas de Vestir

$\checkmark$ Iniciativa Clúster de Cosméticos

$\checkmark$ Iniciativa Clúster de Industrias Creativas y Contenidos

$\checkmark$ Iniciativa Clúster de Turismo de Negocios y Eventos

$\checkmark$ Iniciativa Clúster de Software y TI

$\checkmark$ Iniciativa Clúster de Comunicación Grafica

$\checkmark$ Iniciativa Clúster de Joyería y Bisutería

$\checkmark$ Iniciativa Clúster de Energía Eléctrica

$\checkmark$ Iniciativa Clúster de Gastronomía

$\checkmark$ Iniciativa Clúster de Música

$\checkmark$ Iniciativa Clúster de Salud

$\checkmark$ Iniciativa Clúster de Lácteos
} 


\section{$\checkmark$ Iniciativa Clúster de Cuero, Calzado y Marroquinería}

Este trabajo de investigación se va centrar en la Iniciativa Clúster del sector industrial del Cuero, Calzado y Marroquinería en Bogotá, ya que este sector fue uno de los más afectados por la llegada al país de los productos asiáticos. Por lo tanto, los líderes de este sector en acompañamiento de la Cámara de Comercio de Bogotá crearon la Iniciativa Clúster del sector del cuero, calzado y marroquinería en el año 2012, con el fin generar una barrera competitiva como lo da a conocer la (Camara de Comercio de Bogotá, 2012) se enfoca en:

Establecer diferenciales competitivos en diseño, confort e innovación en los productos para abastecer la demanda interna y generar una aproximación acertada, impulsar la productividad y eficiencia de las empresas del Clúster y el fortalecimiento de su capital humano y articular la investigación académica con las necesidades empresariales para el desarrollo tecnológico de las empresas.

Adicional, (Plan de negocios del Sector de Cuero, Calzado y Marroquineria, 2013) informa que "El Sector de Cuero, Calzado y Marroquinería en Colombia no cuenta con las condiciones productivas y los encadenamientos necesarios para mantener su participación en el mercado local y competir en mercados internacionales". Actualmente la Iniciativa cuenta con 270 actores entre proveedores, empresas productoras, comercializadores y entidades de apoyo.

Esta iniciativa desde que inicio se esfuerza:

Por consolidar la competitividad de las empresas de la región a partir de su amplia tradición e importancia como principal productor y comercializador de productos en el mercado interno y de exportación, desarrollando beneficios a la cadena, ampliando capacidades en diseño e innovación para la diferenciación, y potencializando las oportunidades de Tratados de Libre Comercio y acuerdos 
comerciales entre la producción local, cadenas comerciales y grandes superficies" (Camara de Comercio de Bogotá, 2014).

El sector de cuero, calzado y marroquinería por medio de su iniciativa logro un desarrollo industrial, especialmente por su alianza entre grandes y pequeñas empresas que muestran la cooperación empresarial y se empiezan a registrar los resultados como son los beneficios.

Esto se alcanzó ya que la iniciativa cuenta con pilares estratégicos, los cuales deben ser acogidos por todos sus integrantes y son la base para que la propuesta valor sea alcanzada, los pilares son los siguientes tomados de (Cluster Bogotá Cuero, Calzado y Marroquinería, 2012):

$\checkmark$ Articulación, Institucionalidad y Normativa por medio de:

- Gestionar alianzas interinstitucionales en función del fortalecimiento competitivo de las empresas del Clúster.

- Promover actividades de encuentro y discusión entre los actores del Clúster como mecanismo para la construcción de consenso.

- Articular acciones y medidas del sector público que promuevan la competitividad de las empresas del Clúster.

- Generar lineamientos y políticas públicas para el desarrollo sectorial.

- Propiciar alianzas público - privadas para incrementar la competitividad de la industria.

$\checkmark$ Fortalecimiento Empresarial y Talento Humano por medio de:

- Desarrollo del talento humano.

- Fortalecer alianzas empresariales para el desarrollo competitivo y la generación de Valor Compartido.

- Focalizar esfuerzos del sector público y de las entidades de apoyo. 
Moda, Diseño y Valor Agregado

- Consolidar una red académica y de innovación que soporte la ampliación de las capacidades de investigación, tecnológica y de innovación en las empresas.

- Promover actividades de difusión y de transferencia tecnológica.

- Identificar instituciones, líneas, grupos y proyectos de investigaciones académicas y tecnológicas relacionadas con las actividades empresariales del Clúster.

- Articular líneas y grupos de investigación con enfoque a la competitividad sectorial.

La Cámara de Comercio por medio de la iniciativa vinculo a una serie de entidades de apoyo y son las siguientes: Programa de transformación productiva, Asociación Colombiana de Industriales del Calzado, el Cuero y sus Manufacturas (ACICAM), Asociación Nacional de Empresarios de Colombia (ANDI), La red global para los profesionales de competitividad, clúster y la innovación (TCI), Red Clúster Colombia, entre otras.

Con los pilares que van enfocados a cumplir la promesa valor es "Consolidar la oferta cuero, calzado y marroquinería de Bogotá con valor agregado, enfoque a consumo interno y países de las Américas en segmentos económicos medio y alto" (Cluster Bogotá Cuero, Calzado y Marroquinería, 2012) y las diferentes entidades que apoyan este clúster se buscar alcanzar cada uno de los pilares de esta iniciativa que son la innovación en producto, productividad, fortalecimiento del capital humano y desarrollo tecnológico que son los beneficios que persigue el clúster y sobre estos nos vamos a basar para medir los beneficios que las empresas encuestadas mencionen que fueron alcanzados. 


\section{Diseño metodológico y Resultados}

\subsection{Estructura metodológica}

En el presente trabajo de grado se emplea una investigación con enfoque investigativo exploratorio y descriptivo. Por lo tanto, vamos detallar como está compuesta la metodología de investigación y que herramientas van hacer implementadas para dar respuesta a nuestros objetivos planteados al inicio.

Una investigación descriptiva como lo describe (Hernández Sampieri, Fernández Collado, \& Baptista Lucio, 2010) "busca especificar propiedades, características y rasgos importantes de cualquier fenómeno que se analice o tendencias de un grupo o población" (p.80); basándonos en este concepto se busca analizar a las empresas fabricantes que pertenecen al clúster del sector del cuero, calzado y marroquinería en Bogotá, para que desde la observación se identifique las causas que llevo a las empresas a pertenecer al clúster y que beneficios han obtenido por su participación. Adicional, la investigación descriptiva trabaja sobre acontecimientos vividos por la muestra selecciona, por lo tanto, la teoría se contrastar con los resultados obtenidos de la investigación para comprobarla y como dice (Tamayo, 2004) "El enfoque se hace sobre conclusiones dominantes o sobre cómo una persona, grupo o cosa conduce o funciona en el presente. La investigación descriptiva trabaja sobre realidades de hecho, y su característica fundamental es la de presentarnos una interpretación correcta”, por esta razón el enfoque descriptivo se va obtener información cuantitativa y cualitativa con la cual podemos definir causales de ingreso, beneficios e indicadores de cumplimiento del clúster.

Adicional, la investigación descriptiva se complementa con una investigación exploratoria como lo menciona (Hernández Sampieri, Fernández Collado, \& Baptista Lucio, 2010) "los estudios exploratorios sirven fundamentalmente para descubrir estudios descriptivos que son útiles para mostrar con precisión los ángulos o dimensiones de un fenómeno, suceso, comunidad, contexto o situación. Y esta clase de estudios el investigador debe ser capaz de definir o visualizar, qué se medirá (conceptos, variables, componentes, etc.)" (p. 80), por lo tanto puede "hallar nuevas ideas estratégicas, ya que 
puede lograr que los entrevistados tengan una mayor libertad en las respuestas para permitirles expresar con comodidad sus pensamientos sobre el tema dentro del proceso investigativo ya que este es flexible" (Baena, 2009); por lo tanto esta unión de enfoques se busca identificar, analizar y detectar información que brinde la oportunidad de establecer sugerencias de mejora a los clúster y su importancia de implementarlo en el sector del cuero, calzado y marroquinería en Bogotá.

Las herramientas que se van a implementar para realizar esta investigación son:

$\checkmark$ Entrevista no estructurada: Se elaboró un cuestionario de preguntas las cuales son flexibles y abiertas con el fin de obtener mayor información, aunque las preguntas siempre van orientadas a responder los objetivos de la investigación.

$\checkmark$ Encuesta descriptiva: Este tipo de encuesta fue implementada con el objetivo de conocer, describir e identificar las características muestra representativa. El cuestionario que se va realizar es autodidáctico ya que no es necesario que el encuestador intervenga para la solución, este está compuesto por 8 preguntas cerradas de respuesta sugerida y de valoración.

$\checkmark$ Observación en campo: Es un procedimiento de recolección de datos e información que consiste en observar hechos y realidades sociales presentes.

$\checkmark$ Revisión documental: Es la revisión literaria sobre las diferentes teorías e información sobre el tema de investigación.

Estos métodos fueron los seleccionados ya que permiten conocer actitudes, hábitos y conductas con el fin de dar respuesta a los objetivos de esta investigación. Para demostrar los dos primeros objetivos que son identificar los beneficios e indicadores de cumplimiento del clúster se van medir con el método de encuesta descriptiva y entrevista no estructurada y para demostrar el tercero y cuarto objetivo que son sugerencias de mejora al clúster y la importancia de este, lo cual se va obtener la unión de todas las herramientas implementadas en la investigación. 


\subsection{Muestra de la investigación}

De acuerdo al tipo de metodología de investigación implementada para el desarrollo de este trabajo de grado, se utilizó como herramienta la aplicación de encuestas a las empresas productoras del clúster del sector del calzado, cuero y marroquinería de Bogotá, para la comprobación y efectividad en los resultados.

Se tuvo en cuenta definir la muestra representativa para la aplicación de encuestas a 30 empresas productoras que integran el clúster. Dentro de estas empresas se encuentran productoras de calzado y transformación del cuero ubicados en la ciudad de Bogotá.

En el desarrollo de esta investigación se implementó una muestra no probabilística discrecional, donde se escogió la población para obtener resultados más acertados según las variables tenidas en cuenta para este trabajo de grado. Este tipo de muestreo permitió identificar cuáles son los beneficios más importantes que se pueden obtener al integrar al clúster.

Además, es importante resaltar que al escoger la población para la muestra permite tener una visión más clara de cómo funciona el clúster y cómo impacta en las empresas productoras del sector del calzado, cuero y marroquinería.

Para seleccionar el tamaño de la muestra aplicamos la siguiente ecuación al total de las empresas productoras del clúster que son 90 , con lo cual buscamos determinar la muestra correcta para obtener resultados confiables:

$$
n=\frac{k^{2} * p * q * N}{\left(e^{2} *(N-1)\right)+K^{2} * P * Q}
$$

n: Es el tamaño de la población o universo.

k: Nivel de confianza. Lo habitual es entre el 95\% = 1,96-99\%=2,58

e: Es el error maestral deseado. Oscila en entre el 5\% 
p: es la proporción de individuos que poseen en la población la característica de estudio. Este dato es generalmente desconocido y se suele suponer que es 0.5 que es la opción más segura.

q: es la proporción de individuos que no poseen esa característica, es decir, es 1.

n: es el tamaño de la muestra (número de encuestas que vamos a hacer).

(Feed Back Networks, 2013)

$$
30=\frac{1,96^{2} * 0.5 * 1 * 91}{\left(0.5^{2} *(91-1)\right)+1,96^{2} * 0.5 * 1}
$$

Según el cálculo realizado la muestra representativa debe tener un tamaño de 30 empresas productoras que integran el clúster del sector del cuero, calzado y marroquinería, por lo tanto, esta muestra brinda el suficiente grado de confiabilidad para determinar que la información obtenida verídica. Y poder identificar los beneficios que se obtienen al participar de un clúster. Adicional, realizamos una entrevista al Director de la Iniciativa Clúster sector del cuero, calzado y marroquinería al Doctor Juan Diego Cardona Echeverry, esto con el fin de obtener más información sobre los beneficios e importancia del clúster para las empresas productoras de este sector. 


\subsection{Resultados}

\subsubsection{Análisis de las encuestas}

Se realizó una aplicación de 30 encuestas a empresas que corresponden al 30\% de las empresas productoras que hacen parte del Clúster del sector del Cuero, Calzado y Marroquinería en Bogotá. Donde se busca identificar los beneficios que se obtienen al pertenecer a un clúster. Adicional, realizar un comparativo de los beneficios obtenidos de la participación en el clúster, teniendo en cuenta la antigüedad de las empresas en este.

Tabla 1. Elaboración propia - Relación de las empresas productoras encuestadas.

\begin{tabular}{|c|c|c|c|c|c|c|c|}
\hline No & $\begin{array}{l}\text { Nombre } \\
\text { Empresa }\end{array}$ & Actividad Económica & $\begin{array}{c}\text { Tiempo de } \\
\text { Permanencia en } \\
\text { Clúster }\end{array}$ & $\begin{array}{c}\text { Fecha } \\
\text { Aplicación } \\
\text { Encuesta }\end{array}$ & Tipo de sociedad & $\begin{array}{c}\text { No } \\
\text { empleados }\end{array}$ & Subsectores \\
\hline 1 & Abela SAS & $\begin{array}{l}\text { Fabricación y } \\
\text { comercialización de } \\
\text { calzado }\end{array}$ & 2 Años & 22 -oct-16 & $\begin{array}{c}\text { Sociedades por } \\
\text { acciones } \\
\text { simplificadas SAS }\end{array}$ & 2 & $\begin{array}{l}\text { Calzado y } \\
\text { cuero }\end{array}$ \\
\hline 2 & Anyinzan & Diseño de productos & 1 Año & 22 -oct-16 & $\begin{array}{c}\text { Sociedades por } \\
\text { acciones } \\
\text { simplificadas SAS }\end{array}$ & 5 & $\begin{array}{c}\text { Cuero y } \\
\text { marroquinería }\end{array}$ \\
\hline 3 & $\begin{array}{l}\text { Arte \& Diseño } \\
\text { en Pieles SAS }\end{array}$ & $\begin{array}{l}\text { Fabricación de calzado } \\
\text { y bolsos en cuero y } \\
\text { dotaciones } \\
\text { empresariales dama }\end{array}$ & 4 Años & 22-oct-16 & $\begin{array}{l}\text { Sociedades por } \\
\text { acciones } \\
\text { simplificadas SAS }\end{array}$ & 4 & $\begin{array}{c}\text { Calzado cuero } \\
\text { y } \\
\text { marroquinería }\end{array}$ \\
\hline 4 & Calzado Cruz & $\begin{array}{l}\text { Diseño y fabricación } \\
\text { de calzado }\end{array}$ & 3 Años & 12-nov-16 & $\begin{array}{c}\text { Sociedades por } \\
\text { acciones } \\
\text { simplificadas SAS }\end{array}$ & 6 & $\begin{array}{l}\text { Calzado y } \\
\text { cuero }\end{array}$ \\
\hline 5 & $\begin{array}{l}\text { Calzado } \\
\text { Gerard }\end{array}$ & $\begin{array}{l}\text { Fabricación de botas } \\
\text { para dama }\end{array}$ & 4 Años & 22 -oct-16 & $\begin{array}{l}\text { Establecimientos } \\
\text { de comercio }\end{array}$ & 7 & $\begin{array}{l}\text { Calzado y } \\
\text { cuero }\end{array}$ \\
\hline 6 & Calzado Iony & Fabricación de calzado & 1 Año & 12-nov-16 & $\begin{array}{l}\text { Establecimientos } \\
\text { de comercio }\end{array}$ & 5 & $\begin{array}{l}\text { Calzado y } \\
\text { cuero }\end{array}$ \\
\hline 7 & Calzado Kira & $\begin{array}{l}\text { Fabricación de calzado } \\
\text { en cuero mujer botas }\end{array}$ & 3 Años & 12-nov-16 & $\begin{array}{l}\text { Establecimientos } \\
\text { de comercio }\end{array}$ & 5 & $\begin{array}{l}\text { Calzado y } \\
\text { cuero }\end{array}$ \\
\hline 8 & $\begin{array}{l}\text { Calzado Siete } \\
\text { Cueros SA }\end{array}$ & $\begin{array}{l}\text { Fabricantes de calzado } \\
\text { industrial }\end{array}$ & 3 Años & 12-nov-16 & Sociedad anónima & 10 & $\begin{array}{l}\text { Calzado y } \\
\text { cuero }\end{array}$ \\
\hline 9 & $\begin{array}{l}\text { Calzado Vitos } \\
\text { SAS }\end{array}$ & $\begin{array}{l}\text { Fabricación de calzado } \\
\text { de dama }\end{array}$ & 4 Años & 22 -oct-16 & $\begin{array}{c}\text { Sociedades por } \\
\text { acciones } \\
\text { simplificadas SAS }\end{array}$ & 9 & $\begin{array}{l}\text { Calzado y } \\
\text { cuero }\end{array}$ \\
\hline 10 & $\begin{array}{l}\text { Calzados } 3025 \\
\text { S.A }\end{array}$ & $\begin{array}{l}\text { Fabricante de calzado } \\
\text { industrial }\end{array}$ & 3 Años & 12-nov-16 & Sociedad anónima & 15 & $\begin{array}{l}\text { Calzado y } \\
\text { cuero }\end{array}$ \\
\hline 11 & $\begin{array}{l}\text { Calzatore } \\
\text { Hemisi Ltda }\end{array}$ & Fabricante de calzado & 3 Años & 12-nov-16 & Sociedad limitada & 6 & $\begin{array}{l}\text { Calzado y } \\
\text { cuero }\end{array}$ \\
\hline 12 & $\begin{array}{l}\text { Creaciones } \\
\text { Yamile B\&R } \\
\text { SAS }\end{array}$ & Fabricante de calzado & 4 Años & 22-oct-16 & $\begin{array}{c}\text { Sociedades por } \\
\text { acciones } \\
\text { simplificadas SAS }\end{array}$ & 7 & $\begin{array}{l}\text { Calzado y } \\
\text { cuero }\end{array}$ \\
\hline 13 & $\begin{array}{l}\text { Cueros } \\
\text { Terranova }\end{array}$ & $\begin{array}{l}\text { Curtido y adobo de } \\
\text { cueros }\end{array}$ & 3 Años & 12-nov-16 & $\begin{array}{l}\text { Establecimientos } \\
\text { de comercio }\end{array}$ & 7 & Cuero \\
\hline 14 & $\begin{array}{l}\text { Curtiembres } \\
\text { Gales }\end{array}$ & $\begin{array}{l}\text { Empresa dedicada al } \\
\text { curtido y terminación }\end{array}$ & 4 Años & 22-oct-16 & $\begin{array}{l}\text { Establecimientos } \\
\text { de comercio }\end{array}$ & 9 & Cuero \\
\hline
\end{tabular}




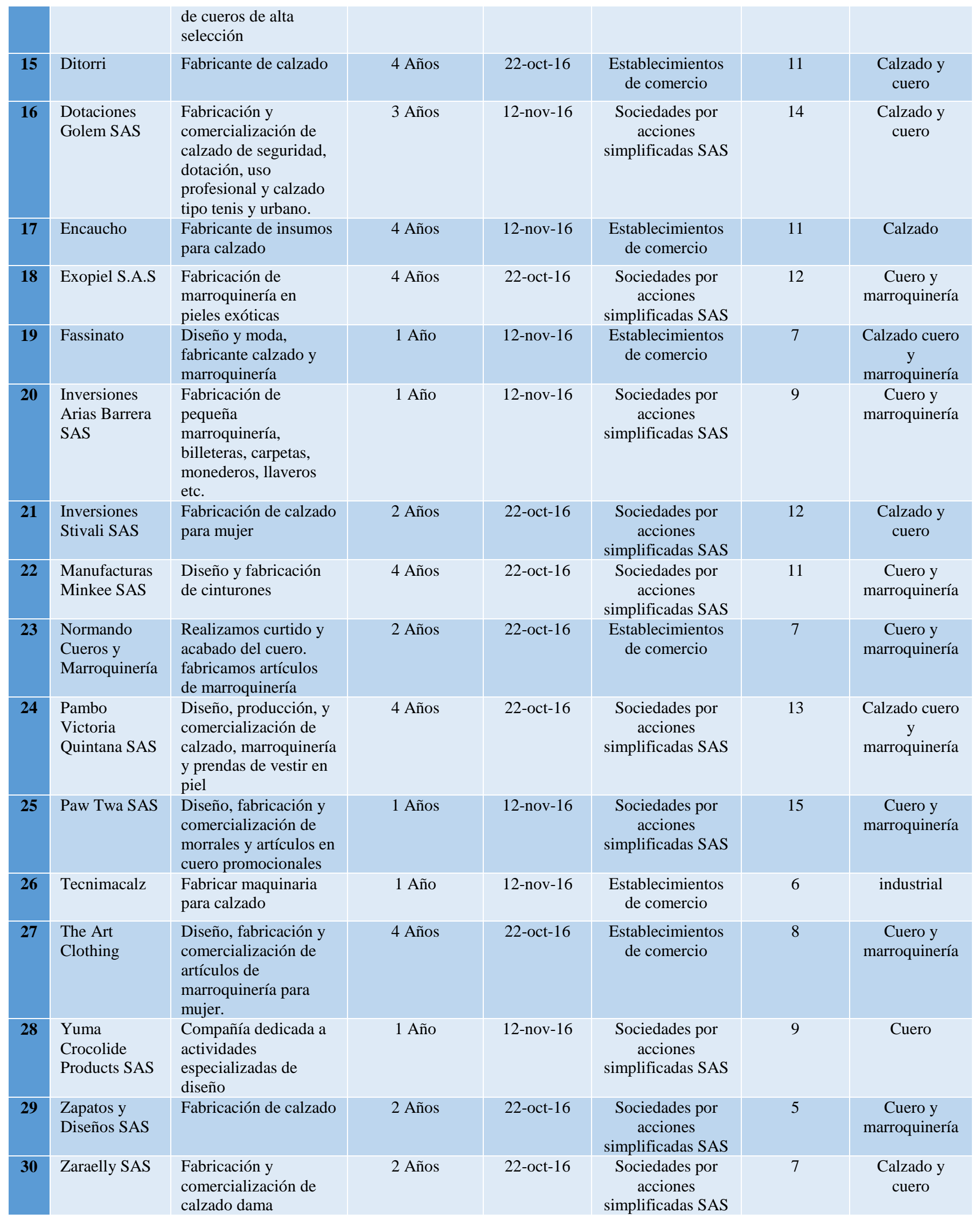


En la tabla No.1 se evidencia las 30 empresas que fueron seleccionadas para la aplicación de la encuesta, la herramienta de investigación seleccionada para la recolección de información. En esta tabla se encuentra los siguientes datos:

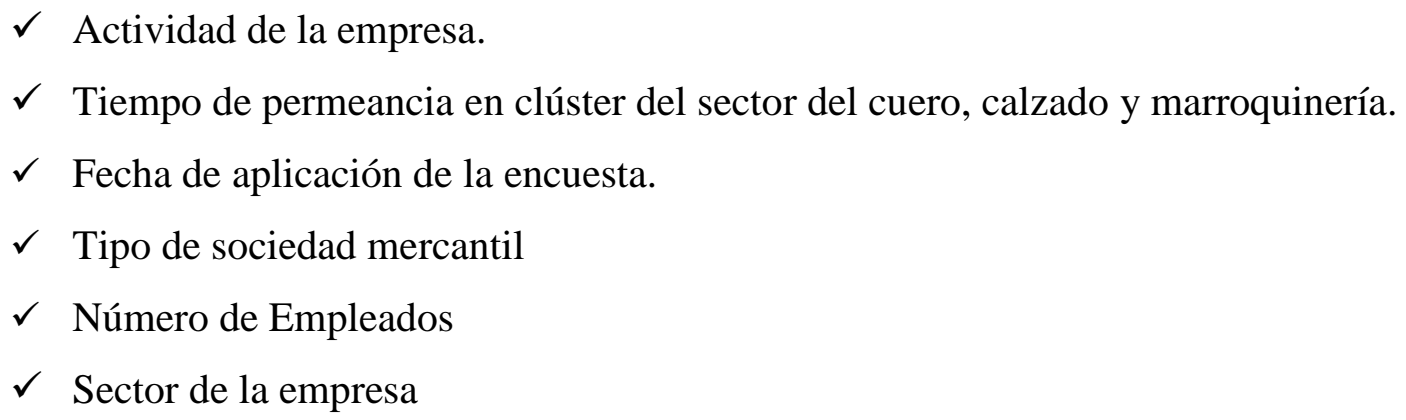

De la información obtenida de las empresas que componen la muestra de la investigación se pudo calcular el promedio de trabajadores con el fin determinar si son empresas PYMES o grandes, el resultado obtenido fue de nueve trabajadores por cada empresa, por lo tanto, se evidencia que muestra está compuesta por empresas PYMES.

De esta misma información se pudo determinar que las empresas que componen en el clúster realizan desde una hasta las cuatro actividades de la cadena productiva del cuero, esta información la podemos validar con la revisión literaria donde se explica que el sector está conformado en Colombia teniendo en cuenta la cadena productiva de la principal materia prima que es el cuero, por esta razón el clúster abarca todas las empresas que trabajen con el cuero sin importar que parte del proceso realice, dado que lo que buscar el clúster es una integración de la cadena productiva.

\section{Tabulación de las encuestas}

A continuación, después de realizar las encuestas, se presentan los resultados mediante gráficas porcentuales y tablas de tabulación. 
Pregunta No. 1 ¿La empresa ha asistido a una capacitación sobre clúster?

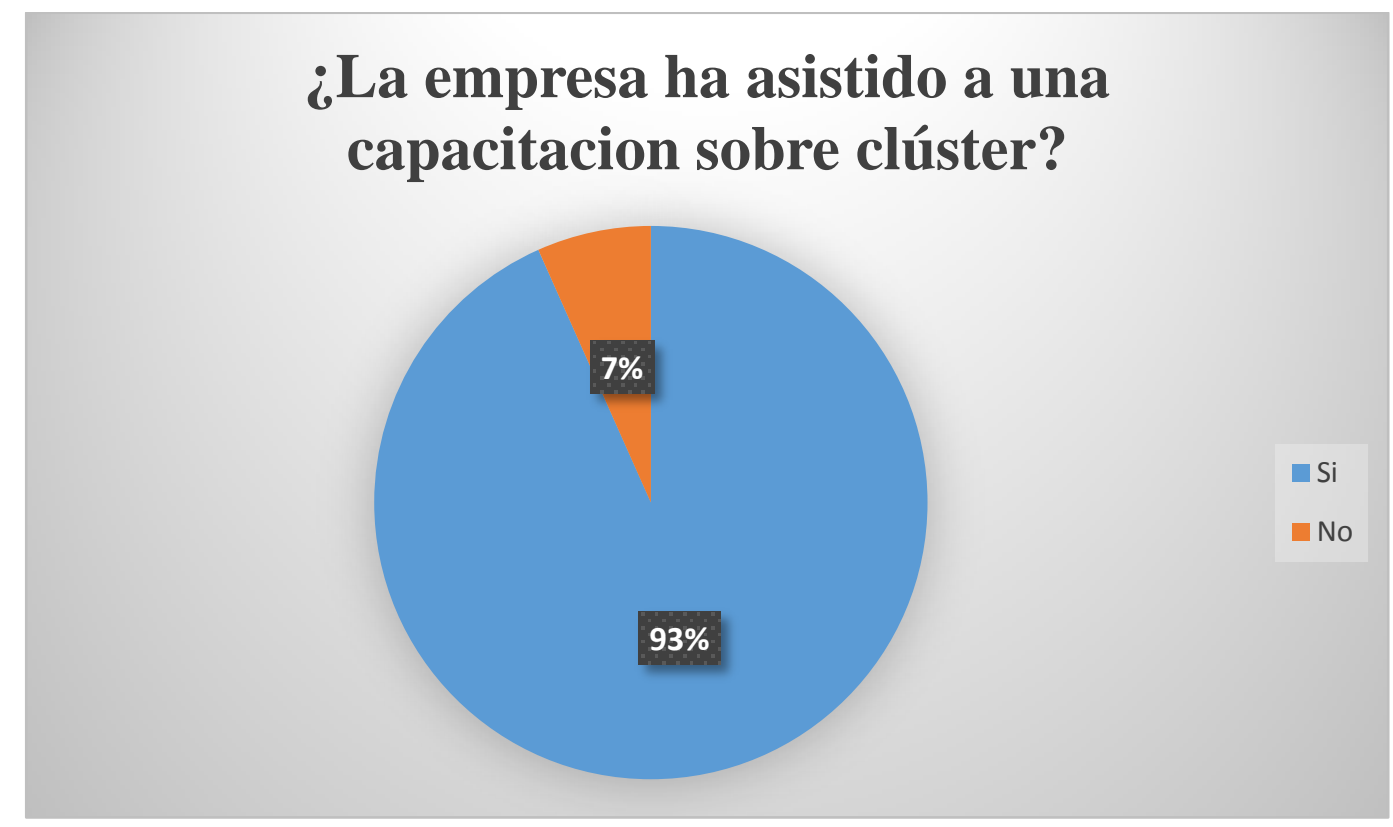

Grafica 1. Asistencia de empresas del clúster a capacitación sobre clúster

\begin{tabular}{|l|r|r|}
\hline \multirow{2}{*}{ Respuesta } & \multicolumn{2}{|c|}{ Total } \\
\cline { 2 - 3 } & Cantidad & \multicolumn{1}{|c|}{$\%$} \\
\hline $\mathrm{Si}$ & 28 & $93 \%$ \\
\hline No & 2 & $7 \%$ \\
\hline Total & $\mathbf{3 0}$ & $\mathbf{1 0 0 \%}$ \\
\hline
\end{tabular}

Tabla 2 Tabulación de Pregunta No 1 - ¿La empresa ha asistido a una capacitación sobre clúster?

Interpretación:

El 93\% de las empresas productoras que integran el clúster han asistido a una capacitación de las iniciativas clúster para conocer sus beneficios y como funciona.

El 7\% de las empresas productoras encuestadas notifico no haber asistido a una capacitación por falta de tiempo y recursos estos ligados al tamaño de la empresa.

De lo anterior se evidencia que las empresas productoras asisten a charlas y capacitaciones acerca del clúster, una vez se integran al clúster, dentro de estas charlas o mesas de ayuda van conociendo más de sus beneficios y los alcances que pueden llegar a obtener, adicional se dan a conocer que otras entidades de apoyo ofrecen formación y capacitación para promover el crecimiento del recurso humano. 
Pregunta No. 2 ¿Ha sido útil para la empresa participar del clúster del sector del Cuero, Calzado y Marroquinería?

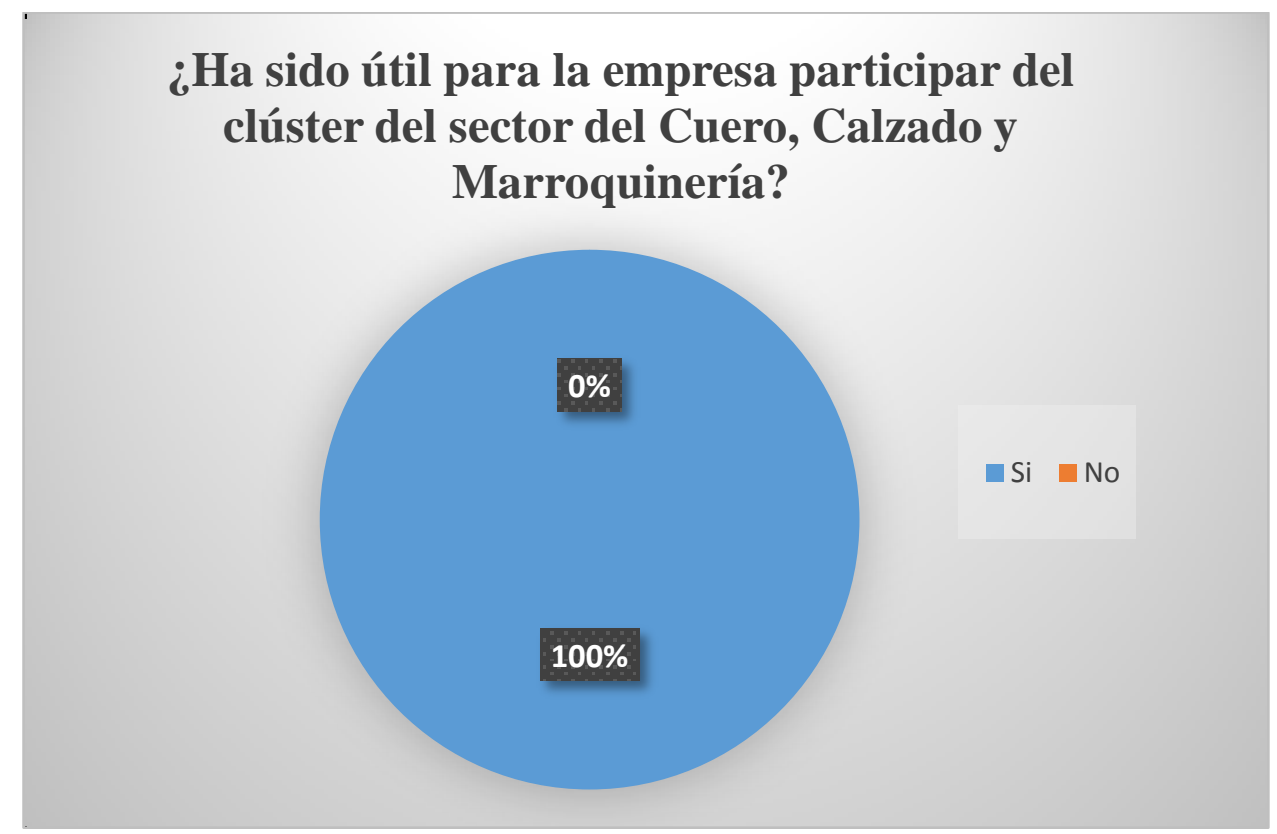

Grafica 2. Ha sido útil la partición en clúster

\begin{tabular}{|l|r|r|}
\hline \multirow{2}{*}{ Respuesta } & \multicolumn{2}{|c|}{ Total } \\
\cline { 2 - 3 } & Cantidad & \multicolumn{1}{c|}{$\%$} \\
\hline $\mathrm{Si}$ & 30 & $100 \%$ \\
\hline No & 0 & $0 \%$ \\
\hline Total & $\mathbf{3 0}$ & $\mathbf{1 0 0 \%}$ \\
\hline
\end{tabular}

Tabla 3. Tabulación de Pregunta No 2 - ¿Ha sido útil para la empresa participar del clúster del sector del Cuero, Calzado y Marroquinería?

Interpretación:

El 100\% de las empresas productoras encuestadas manifiestan que el clúster como herramienta les ha permitido solucionar problemas y suplir necesidades a través del trabajo conjunto con otras empresas, ayudándoles a tomar decisiones apropiadas para sus empresas. 
Las empresas encuestadas notifican la importancia y la gran ayuda que ha sido la herramienta clúster para sus empresas, manifiestan que luego de haber atravesado por una crisis, los clústers han sido una herramienta para reforzar sus lazos empresariales y retomar la productividad y rentabilidad de sus productos.

Además, les ha permitido el crecimiento organizacional a través de la capacitación en procesos de producción que han influenciado en la calidad en sus productos y el manejo de desperdicios.

Pregunta No. 3 ¿La empresa ha recibido asesoría de alguna entidad de apoyo que pertenezca al clúster del sector del Cuero, Calzado y Marroquinería?

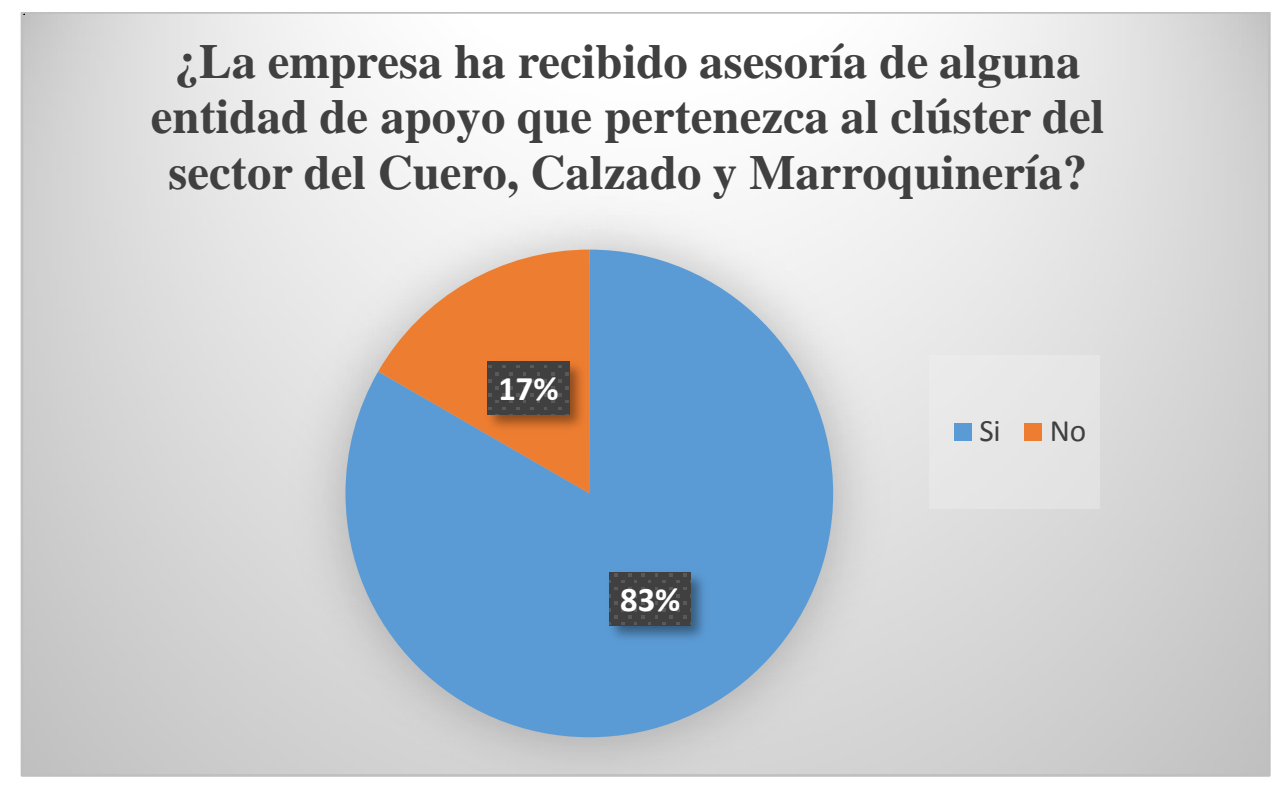

Grafica 3. Asesorías de las entidades de apoyo del clúster

\begin{tabular}{|l|r|r|}
\hline \multirow{2}{*}{ Respuesta } & \multicolumn{2}{|c|}{ Total } \\
\cline { 2 - 3 } & Cantidad & \multicolumn{1}{c|}{$\%$} \\
\hline $\mathrm{Si}$ & 25 & $83 \%$ \\
\hline No & 5 & $17 \%$ \\
\hline Total & $\mathbf{3 0}$ & $\mathbf{1 0 0 \%}$ \\
\hline
\end{tabular}

Tabla 4. Tabulación de Pregunta No 3 - ¿La empresa ha recibido asesoría de alguna entidad de apoyo que pertenezca al clúster del sector del Cuero, Calzado y Marroquinería? 
Interpretación:

El 25\% de las empresas productoras encuestadas notifico haber recibido asesorías acerca de cómo trabajar en una red clúster, para alcanzar el beneficio común del sector.

El 5\% de las empresas productoras encuestadas notifico no haber recibido asesorías por parte de una entidad de apoyo, manifestando que no tenían conocimiento de las entidades que ofrecen asesoría.

Las empresas manifiestan que han recibido una mayor asesoría por parte de la Cámara de Comercio de Bogotá, quienes lideran actualmente la iniciativa, y su vez en dichas asesorías se evidencia que es la misma entidad quien los remite a otras entidades de apoyo sea para asesoría o para capacitación en diversos cursos desde innovación en productos hasta manejo de finanzas e inversión.

Pregunta No. 4 ¿Cómo la empresa conoció el clúster del sector del Cuero, Calzado y Marroquinería?

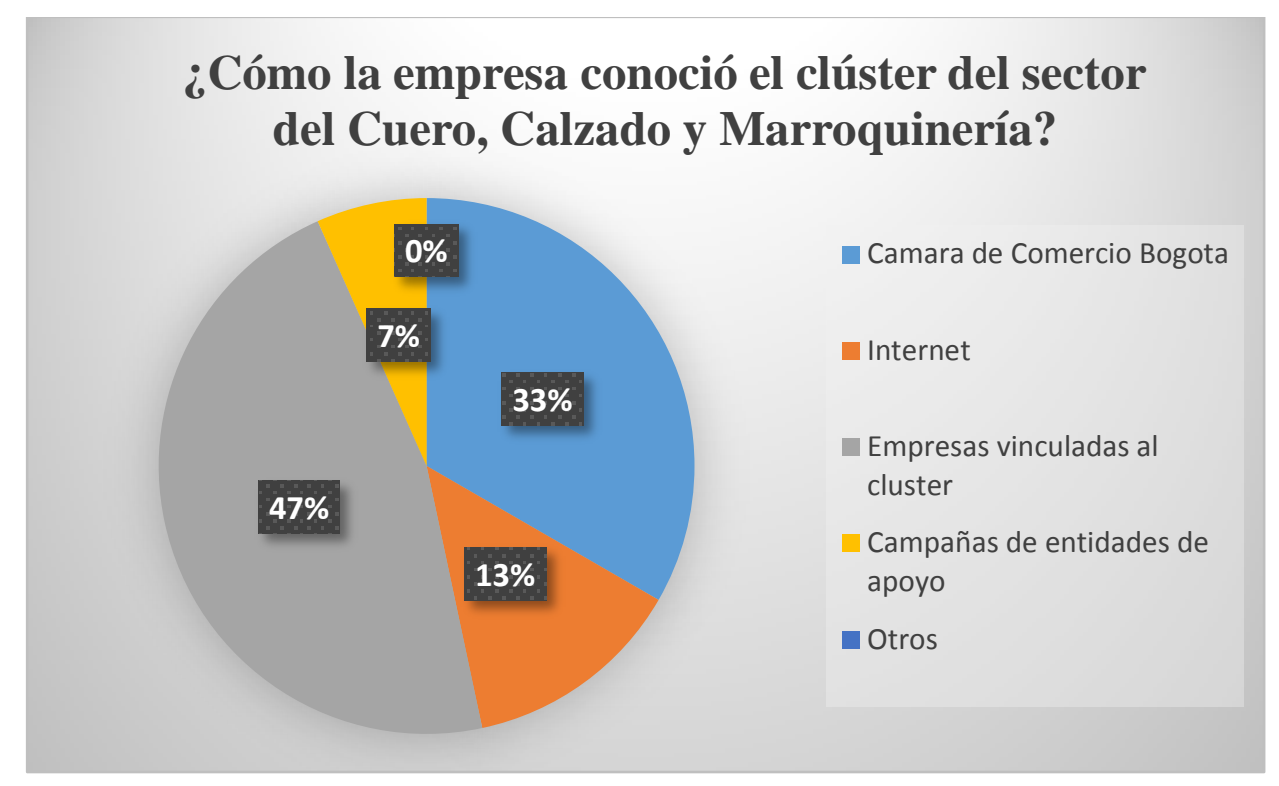

Grafica 4. Motivos por los que empresa conoció el clúster 


\begin{tabular}{|l|r|r|}
\hline \multirow{2}{*}{\multicolumn{1}{|c|}{ Respuesta }} & \multicolumn{2}{c|}{ Total } \\
\cline { 2 - 3 } & Cantidad & \multicolumn{1}{c|}{$\%$} \\
\hline Cámara de Comercio Bogotá & 10 & $33 \%$ \\
\hline Internet & 4 & $13 \%$ \\
\hline Empresas vinculadas al clúster & 14 & $47 \%$ \\
\hline Campañas de entidades de apoyo & 2 & $7 \%$ \\
\hline Otros & 0 & $0 \%$ \\
\hline Total & $\mathbf{3 0}$ & $\mathbf{1 0 0 \%}$ \\
\hline
\end{tabular}

Tabla 5. Tabulación de Pregunta No 4 - ¿Cómo la empresa conoció el clúster del sector del Cuero, Calzado y Marroquinería?

Interpretación:

El $47 \%$ de las empresas productoras encuestadas notifica haber conocido acerca del clúster por otras empresas vinculadas al clúster.

El 33\% de las empresas productoras encuestadas notifica haber conocido a cerca del clúster por la Cámara de Comercio Bogotá.

El 13\% de las empresas productoras encuestadas notifica haber conocido a cerca del clúster por Internet.

El 7\% de las empresas productoras encuestadas notifica haber conocido a cerca del clúster por Campañas de las diferentes entidades de apoyo.

En cuanto la información se evidencia que aún hay muchos vacíos en su difusión, ya que no son muchos los medios que permiten conocer acerca de los clúster, sin embargo manifiestan que lo que los llevo a estar integrados y conocer de los clúster fue la crisis por la cual a atravesaron, ya que por iniciativa de la Cámara de Comercio de Bogotá se obtuvo información de lo que se quería hacer, sin embargo la gran influencia han sido las empresas que ya pertenecían al clúster la que hicieron que la red de alianzas creciera para un trabajo conjunto y cooperativo. 
Pregunta No.5. Califique el clúster del sector del Cuero, Calzado y Marroquinería en Bogotá

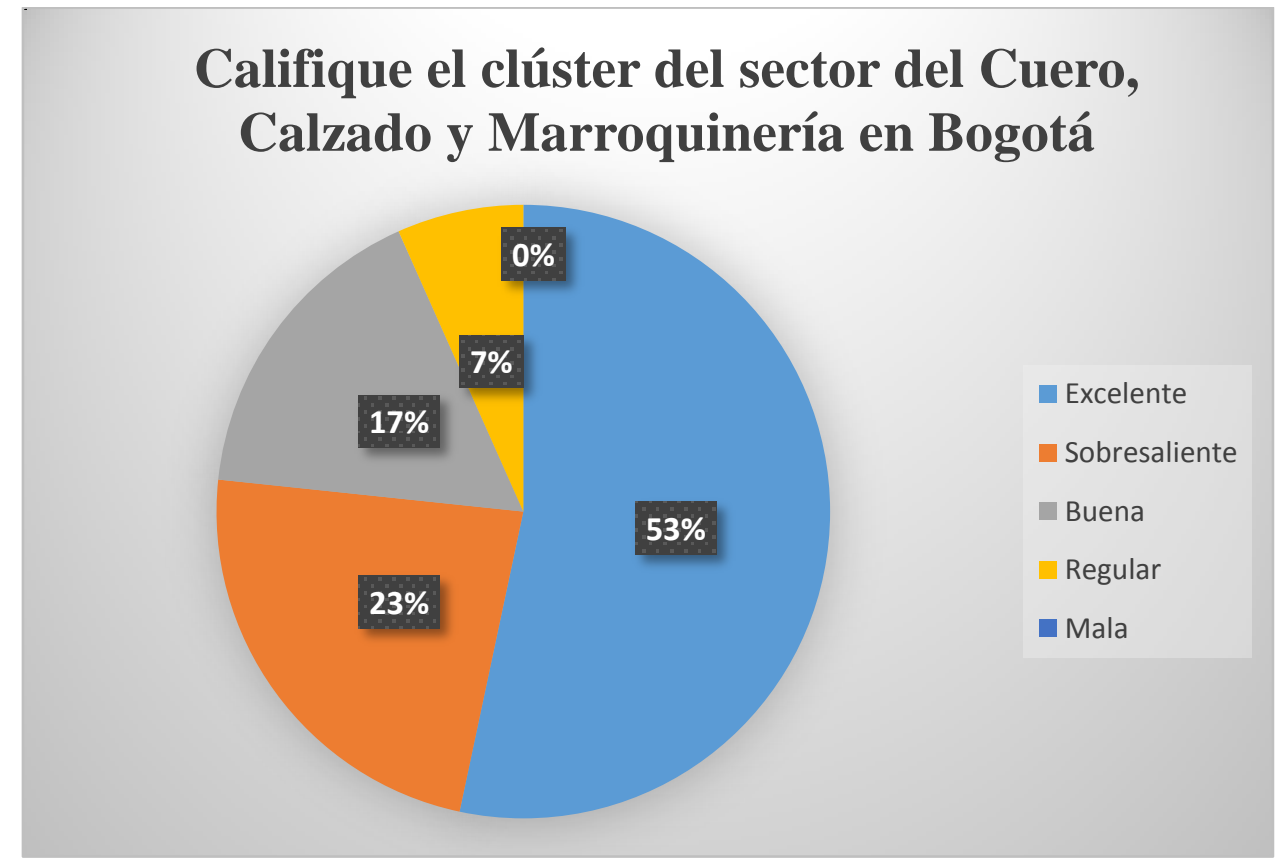

Grafica 5. Calificación del clúster del sector del cuero, calzado y marroquinería

\begin{tabular}{|l|r|r|}
\hline \multirow{2}{*}{\multicolumn{1}{c|}{ Respuesta }} & \multicolumn{2}{|c|}{ Total } \\
\cline { 2 - 3 } & Cantidad & \multicolumn{1}{c|}{$\%$} \\
\hline Excelente & 16 & $53 \%$ \\
\hline Sobresaliente & 7 & $23 \%$ \\
\hline Buena & 5 & $17 \%$ \\
\hline Regular & 2 & $7 \%$ \\
\hline Mala & 0 & $0 \%$ \\
\hline Total & $\mathbf{3 0}$ & $\mathbf{1 0 0 \%}$ \\
\hline
\end{tabular}

Tabla 6. Tabulación de Pregunta No 5 - Califique el clúster del sector del Cuero, Calzado y Marroquinería en Bogotá

Interpretación:

El 53\% de las empresas productoras encuestadas califica Excelente el clúster.

El 23\% de las empresas productoras encuestadas califica Sobresaliente el clúster.

El 17\% de las empresas productoras encuestadas califica Bueno el clúster. 
El 7\% de las empresas productoras encuestadas califica Regular el clúster.

A partir de los cambios que han atravesado las empresas productoras del cuero, calzado y marroquinería, hay una respuesta que supera el 50\% notificando que la iniciativa clúster les parece excelente debido a los beneficios obtenido, adicional se logra evidenciar que dan esa calificación está conformada por las empresas que tienen más antigüedad en el clúster y han podido ver reflejado mayores beneficios para sus empresas.

Pregunta No.6. ¿Con que tipo de empresas ha tenido mayor relación en clúster del sector del cuero, calzado y marroquinería?

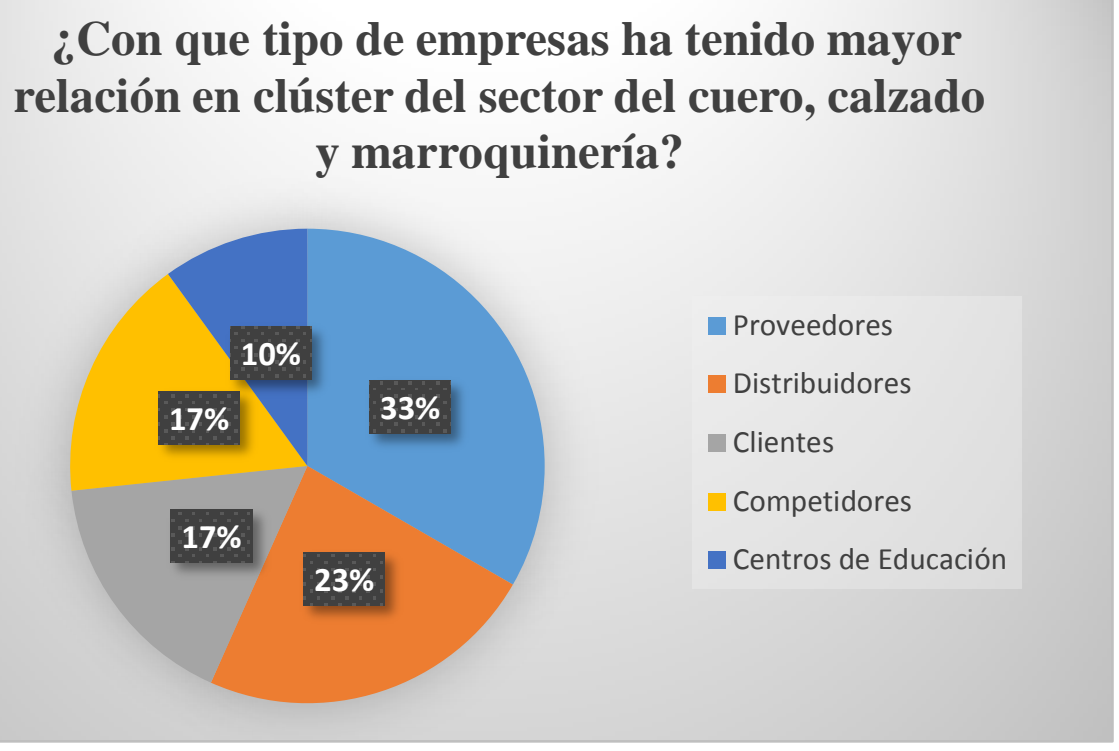

Grafica 6. Tipos de empresa con los que ha tenido relación en el clúster

\begin{tabular}{|l|r|r|}
\hline \multirow{2}{*}{\multicolumn{1}{c|}{ Respuesta }} & \multicolumn{2}{|c|}{ Total } \\
\cline { 2 - 3 } & Cantidad & \multicolumn{1}{c|}{$\%$} \\
\hline Proveedores & 10 & $33 \%$ \\
\hline Distribuidores & 7 & $23 \%$ \\
\hline Clientes & 5 & $17 \%$ \\
\hline Competidores & 5 & $17 \%$ \\
\hline Centros de Educación & 3 & $10 \%$ \\
\hline Total & $\mathbf{3 0}$ & $\mathbf{1 0 0 \%}$ \\
\hline
\end{tabular}

Tabla 7. Tabulación de Pregunta No 6 - ¿Con que tipo de empresas ha tenido mayor relación en clúster del sector del cuero, calzado y marroquinería? 
Interpretación:

Las empresas productoras encuestadas notifican que el foco de sus relaciones se encuentra en el siguiente orden:

1. Proveedores

2. Distribuidores

3. Clientes

4. Competidores

5. Centros de educación

Teniendo en cuenta que las empresas encuestadas son productoras, se logra evidenciar que el foco de sus relaciones son los Proveedores, quienes les han permitido reducir sus costos de producción y formar de financiación acordes a sus necesidades en pro de una relación de gana-gana. Por otro lado, el abastecimiento del mercado nacional también se ha logrado no solo a sus puntos de venta sino a la distribución de sus productos, por lo cual sus Distribuidores han jugado un rol importante que le ha permitido posicionarse en el mercado nacional. 
Pregunta No.7. ¿Qué beneficio ha obtenido la empresa con el clúster del sector del Cuero, Calzado y Marroquinería?

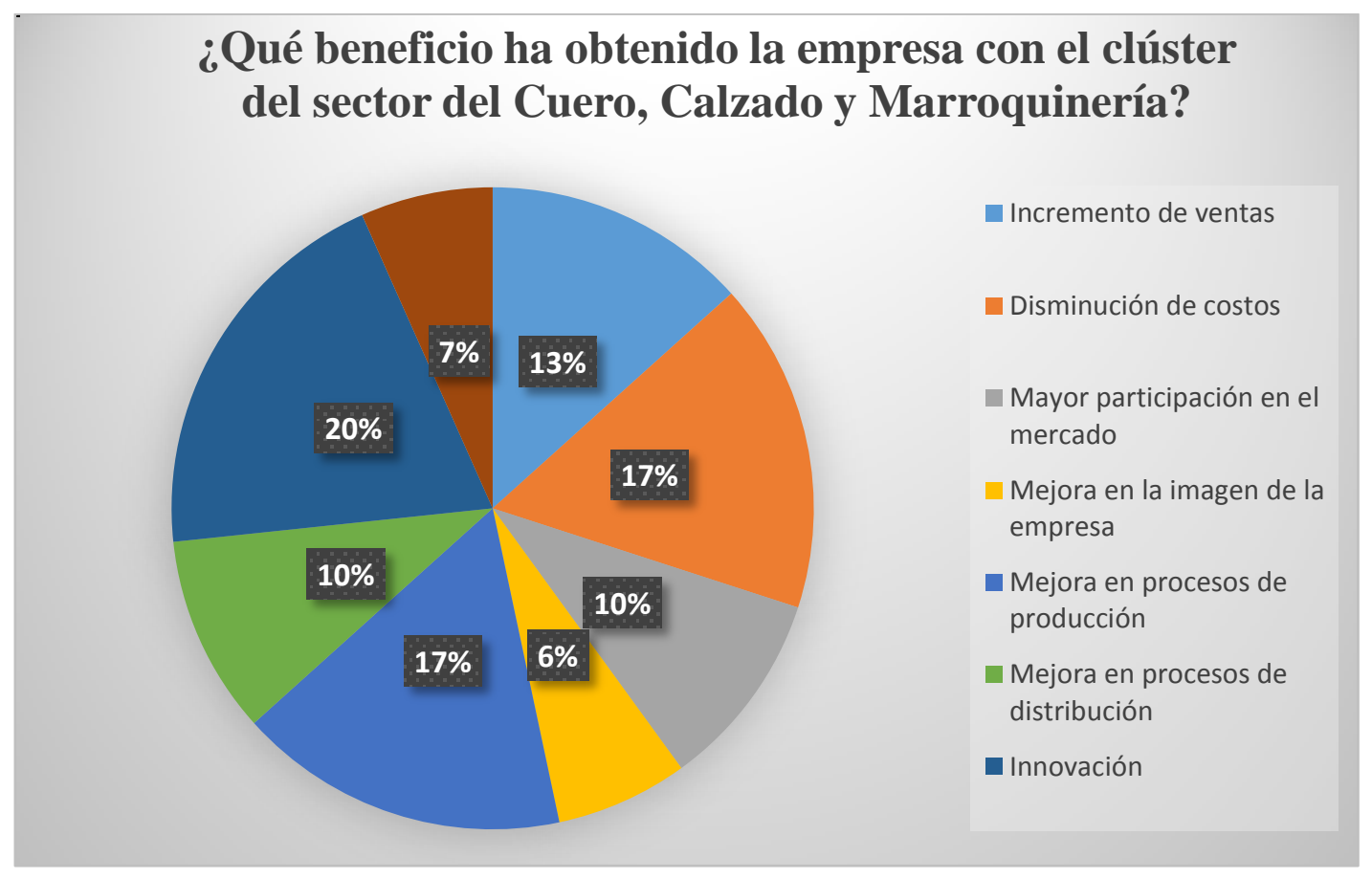

Grafica 7. Beneficio obtenido de la empresa en el clúster

\begin{tabular}{|l|r|r|}
\hline \multirow{2}{*}{\multicolumn{1}{c|}{ Respuesta }} & \multicolumn{2}{c|}{ Total } \\
\cline { 2 - 3 } & Cantidad & \multicolumn{1}{c|}{$\%$} \\
\hline Incremento de ventas & 4 & $13 \%$ \\
\hline Disminución de costos & 5 & $17 \%$ \\
\hline Mayor participación en el mercado & 3 & $10 \%$ \\
\hline Mejora en la imagen de la empresa & 2 & $7 \%$ \\
\hline Mejora en procesos de producción & 5 & $17 \%$ \\
\hline Mejora en procesos de distribución & 3 & $10 \%$ \\
\hline Innovación & 6 & $20 \%$ \\
\hline Mejora en calidad & 2 & $7 \%$ \\
\hline Total & $\mathbf{3 0}$ & $\mathbf{1 0 0 \%}$ \\
\hline
\end{tabular}

Tabla 8. Tabulación de Pregunta No 7 - ¿Qué beneficio ha obtenido la empresa con el clúster del sector del Cuero, Calzado y Marroquinería? 
Interpretación:

$\checkmark$ El 13\% de las empresas productoras encuestadas notifica que tuvo como beneficio Incremento de sus ventas.

$\checkmark$ El 17\% de las empresas productoras encuestadas notifica que tuvo como beneficio Disminución de costos.

$\checkmark$ El 20\% de las empresas productoras encuestadas notifica que tuvo como beneficio Innovación en diseños en sus productos.

$\checkmark$ El 17\% de las empresas productoras encuestadas notifica que tuvo como beneficio Mejora en procesos de producción gracias a la relación con empresas más grandes.

$\checkmark$ El 10\% de las empresas productoras encuestadas notifica que tuvo como beneficio una Mayor participación en el mercado.

$\checkmark$ El 10\% de las empresas productoras encuestadas notifica que tuvo como beneficio Mejora en sus procesos de distribución.

$\checkmark$ El 7\% de las empresas productoras encuestadas notifica que tuvo como beneficio Mejora en la calidad de sus productos.

$\checkmark \mathrm{El} 7 \%$ de las empresas productoras encuestadas notifica que tuvo como beneficio Mejora en la imagen de la empresa.

Las empresas han logrado una gran variedad de beneficios, pero existen tres que se han destacado, como ejemplo la mejora en procesos ya que han contado con capacitaciones para el recurso humano y han empezado a contar con personal calificado, otro de los beneficios es la innovación en producto y la optimización del material disponible para hacer más rentable su negocio. 
Pregunta No.8. ¿Que lo llevo a integrarse al clúster del sector del Cuero, Calzado y Marroquinería?

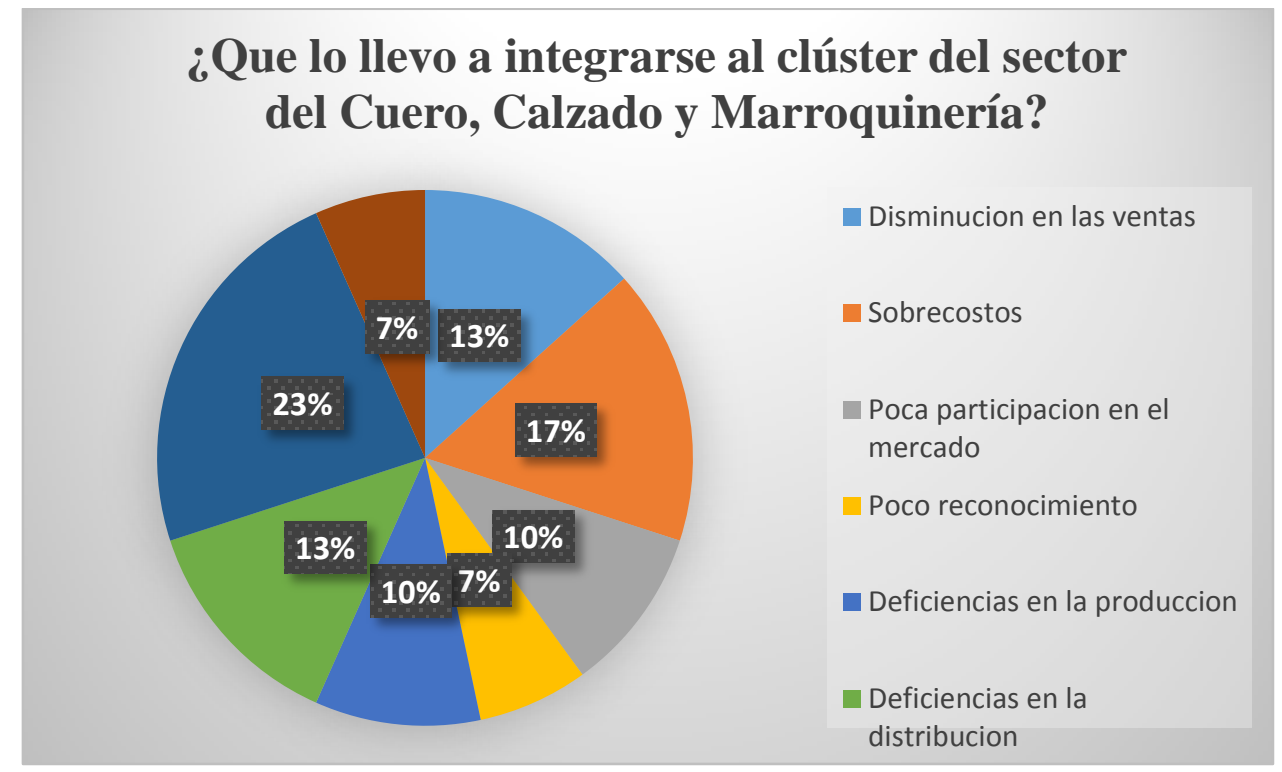

Grafica 8. Motivos de integración de las empresas al clúster del sector del cuero, calzado y marroquinería.

\begin{tabular}{|l|r|r|}
\hline \multirow{2}{*}{\multicolumn{1}{|c|}{ Respuesta }} & \multicolumn{2}{c|}{ Total } \\
\cline { 2 - 3 } & Cantidad & \multicolumn{1}{c|}{$\%$} \\
\hline Disminución en las ventas & 4 & $13 \%$ \\
\hline Sobrecostos & 5 & $17 \%$ \\
\hline Poca participación en el mercado & 3 & $10 \%$ \\
\hline Poco reconocimiento & 2 & $7 \%$ \\
\hline Deficiencias en la producción & 3 & $10 \%$ \\
\hline Deficiencias en la distribución & 4 & $13 \%$ \\
\hline Nuevos productos & 7 & $23 \%$ \\
\hline Mejorar proceso de calidad & 2 & $7 \%$ \\
\hline Total & $\mathbf{3 0}$ & $\mathbf{1 0 0 \%}$ \\
\hline
\end{tabular}

Tabla 9. Tabulación de Pregunta No 8 - ¿Que lo llevo a integrarse al clúster del sector del Cuero, Calzado y Marroquinería?

Interpretación:

$\checkmark$ El 23\% de las empresas productoras encuestadas manifestó que se integró al clúster debido a su falta de productos nuevos.

$\checkmark$ El 17\% de las empresas productoras encuestadas manifestó que se integró al clúster debido a los sobrecostos en su producción. 
$\checkmark$ El 13\% de las empresas productoras encuestadas manifestó que se integró al clúster debido a la disminución en las ventas.

$\checkmark$ El 13\% de las empresas productoras encuestadas manifestó que se integró al clúster debido a las deficiencias en sus procesos de distribución.

$\checkmark$ El 10\% de las empresas productoras encuestadas manifestó que se integró al clúster debido a las deficiencias en sus procesos de producción.

$\checkmark$ El $10 \%$ de las empresas productoras encuestadas manifestó que se integró al clúster debido a la baja participación en el mercado.

$\checkmark$ El 7\% de las empresas productoras encuestadas manifestó que se integró al clúster debido a los procesos de baja calidad.

$\checkmark$ El 7\% de las empresas productoras encuestadas manifestó que se integró al clúster debido al poco reconocimiento de su imagen.

El principal motivo manifestado durante la aplicación de la encuesta evidencio que la falta de innovación en sus productos estaba permitiendo que el producto importado tomara ventaja en el abastecimiento del mercado nacional, no obstante, esto estaba representando disminución en ventas y sobrecostos en almacenamiento y producción.

\subsubsection{Análisis de la entrevista}

El 18 de octubre del 2016 se agenda una cita con el Doctor Juan Diego Cardona Echeverry Director de la Iniciativa Clúster sector del cuero, calzado y marroquinería de la Cámara de Comercio de Bogotá, quien da una nueva forma de ver los clústers, y de conocer que un clúster puede existir, pero si no se trabaja en él no va crecer. Por esta razón la Cámara de Comercio de Bogotá creo el proyecto de Iniciativas Clúster en diferentes sectores entre estos el sector del cuero, calzado y marroquinería, con el fin de ser un intermediario que apoya los diferentes proyectos del clúster y velar por su cumplimiento siendo un ente que busca aliados para la solución de las problemáticas del clúster. 
Se logra identificar numerosos beneficios no solo para el clúster sino para el entorno a este sector. Uno de esos beneficios son las economías de escala ya que ayudan a desarrollar mercados, capacidad de ingresar al mercado y permanecer en el. Otro es la competitividad, que se genera de la innovación en nuevos productos "Fortalecimiento del portafolio" y calidad tanto en producto como en servicio.

En ese orden de ideas, los clústers desarrollan mercados sostenibles apoyados de la innovación, de lo anterior se puede decir que un clúster presenta beneficios para sus miembros, ya que ayudan a emprender proyectos en conjunto.

Junto con esto, si un clúster es exitoso se logra un beneficio compartido, de lo cual se logran formar redes empresariales más fuertes con el fin de generar colectividad en el sector y en el entorno social, que es el propósito de la Cámara de Comercio de Bogotá como lo menciono el Doctor Juan Diego en la entrevista "Formar un tejido empresarial, ya que las empresas son el único generador económico en la sociedad”.

\subsubsection{Análisis de los resultados}

Se realizó un análisis de los resultados obtenidos de las diferentes herramientas implementadas para obtener información de las empresas productoras del sector del cuero, calzado y marroquinería de Bogotá que participan en el clúster de este sector con el objetivo principal de identificar los beneficios del clúster que el principal foco de esta investigación.

Para demostrar el primer objetivo se enfoca en los resultados obtenidos en las encuestas aplicadas a las empresas productoras que son integrantes activos del clúster del sector del cuero, calzado y marroquinería en Bogotá, donde se pudo identificar los beneficios y que motivo a las empresas a vincularse al clúster. 
En consecuencia, a lo anterior se enuncian los beneficios identificados en las empresas productoras que integran el clúster del sector del cuero, calzado y marroquinería:
$\checkmark$ Aumento en ventas
$\checkmark$ Disminución de costos
$\checkmark$ Reconocimiento en el mercado
$\checkmark$ Mejora en la imagen de la empresa
$\checkmark$ Mejora en el proceso de distribución
$\checkmark$ Mejora en el proceso de producción
$\checkmark$ Innovación
$\checkmark$ Mejora en procesos de calidad
$\checkmark$ Productividad

Al tiempo que se identificaron los beneficios del clúster se pudo determinar las situaciones que presentaban las empresas antes de participar en el clúster que son:

\footnotetext{
$\checkmark$ Deficiencia en el proceso de distribución

$\checkmark$ Deficiencia en el proceso de producción

$\checkmark$ Disminución en ventas

$\checkmark$ Procesos de calidad

$\checkmark$ Poca innovación

$\checkmark$ Sobrecostos

$\checkmark$ Baja participación en el mercado
}

Según la información obtenida de las empresas que ingresan el clúster empezaron a generar cambios que se convierten en beneficios, y como se pudo evidenciar en los resultados anteriores, la información obtenida es afirmada con la teoría de la competitividad de Michael Porter donde resalta que la innovación y la productividad son beneficios del clúster. 
En el segundo objetivo se confrontan las dificultades con los beneficios con el fin de establecer indicadores de cumplimiento, en la tabla No 10 se puede observar una comparación entre las dificultades que enfrentaron las empresas encuestas antes de pertenecer al clúster del sector del cuero, calzado y marroquinería de Bogotá frente a los beneficios obtenidos por estas mismas que actualmente integran el clúster.

\begin{tabular}{|l|c|c|l|c|c|c|}
\hline $\begin{array}{c}\text { Dificultad empresarial antes de } \\
\text { pertenecer al clúster }\end{array}$ & $\begin{array}{c}\text { Cantidad } \\
\text { de } \\
\text { empresas }\end{array}$ & $\%$ & $\begin{array}{c}\text { Beneficio empresarial al ingresar } \\
\text { al clúster }\end{array}$ & $\begin{array}{c}\text { Cantidad } \\
\text { de } \\
\text { empresas }\end{array}$ & $\begin{array}{c}\text { \% } \\
\text { Cumplimiento } \\
\text { de la dificultad } \\
\text { empresarial }\end{array}$ \\
\hline Disminución en las ventas & 4 & $13 \%$ & Incremento de ventas & 4 & $13 \%$ & $100 \%$ \\
\hline Sobrecostos & 5 & $17 \%$ & Disminución de costos & 5 & $17 \%$ & $100 \%$ \\
\hline Poca participación en el mercado & 3 & $10 \%$ & Mayor participación en el mercado & 3 & $10 \%$ & $100 \%$ \\
\hline Poco reconocimiento & 2 & $7 \%$ & Mejora en la imagen de la empresa & 2 & $7 \%$ & $100 \%$ \\
\hline Deficiencias en la producción & 3 & $10 \%$ & Mejora en procesos de producción & 5 & $17 \%$ & $167 \%$ \\
\hline Deficiencias en la distribución & 4 & $13 \%$ & Mejora en procesos de distribución & 3 & $10 \%$ & $75 \%$ \\
\hline Nuevos productos & 7 & $23 \%$ & Innovación & 6 & $20 \%$ & $86 \%$ \\
\hline Mejorar proceso de calidad & 2 & $7 \%$ & Mejora en calidad & 2 & $7 \%$ & $100 \%$ \\
\hline \multicolumn{1}{|c|}{ Total } & $\mathbf{3 0}$ & $\mathbf{1 0 0} \%$ & & $\mathbf{3 0}$ & $\mathbf{1 0 0 \%}$ & \\
\hline
\end{tabular}

Tabla 10. Comparación porcentual de las dificultades empresariales antes de pertenecer al clúster vs los beneficios obtenidos al ser integrante del clúster

Según lo anterior se obtuvieron los siguientes resultados:

El $13 \%$ de las empresas productoras encuestadas afirmaron haber incrementado sus ventas, obteniendo un $100 \%$ de cumplimiento de la dificultad presentada.

El $17 \%$ de las empresas productoras encuestadas afirmaron haber disminuido sus costos, obteniendo un $100 \%$ de cumplimiento de la dificultad presentada.

El $10 \%$ de las empresas productoras encuestadas afirmaron tener una mayor participación en el mercado, obteniendo un 100\% de cumplimiento de la dificultad presentada. 
El $7 \%$ de las empresas productoras encuestadas afirmaron haber mejorado la imagen de la empresa, obteniendo un $100 \%$ de cumplimiento de la dificultad presentada.

$\checkmark$ El 10\% de las empresas productoras encuestadas presentaron deficiencias en sus procesos de producción, pero el $17 \%$ de las empresas encuestadas afirmaron haber mejorado sus procesos de producción, obteniendo un $167 \%$ de cumplimiento de la dificultad presentada.

$\checkmark$ El 13\% de las empresas productoras encuestadas presentaron deficiencias en sus procesos de producción, de los cuales el $10 \%$ de las empresas encuestadas presento mejoras en la distribución, obteniendo un $75 \%$ de cumplimiento de la dificultad presentada.

$\checkmark$ El 23\% de las empresas productoras encuestadas presentaron deficiencias en innovación, de las cuales solo el $20 \%$ ha presentado mejoras con nuevos productos y diseños, obteniendo un $86 \%$ de cumplimiento de la dificultad presentada.

$\checkmark$ El 7\% de las empresas productoras encuestadas afirmaron haber mejorado la calidad en sus procesos y productos, obteniendo un 100\% de cumplimiento de la dificultad presentada.

Teniendo en cuenta los resultados anteriores donde los indicadores de cumplimento en su mayoría fueron alcanzados se puede afirmar que el clúster del sector del cuero, calzado y marroquinería en Bogotá es productivo y realmente genera desarrollo para este sector económico estableciendo beneficios que son atractivos para las empresas que aún no hacen parte del clúster.

Adicional, se da a conocer el porcentaje de las dificultades y beneficios sobre el total encuestado, y con estos dos porcentajes se calcula el indicador de cumplimiento de 
superación de la dificultad, teniendo en cuenta lo anterior se presenta de forma resumida la información de la siguiente manera:

Cinco de las dificultades fueron superada en un $100 \%$

$\checkmark$ Una de las dificultades fue superada por el $167 \%$

$\checkmark$ Dos de las dificultades no fueron superadas en su totalidad, pero cabe resaltar que se su porcentaje de cumplimiento supera el $50 \%$

Adicional, en la siguiente gráfica No. 9 se muestra el contraste de las dificultades frente al beneficio obtenido en la permanencia en el clúster del sector del cuero, calzado y marroquinería en Bogotá.

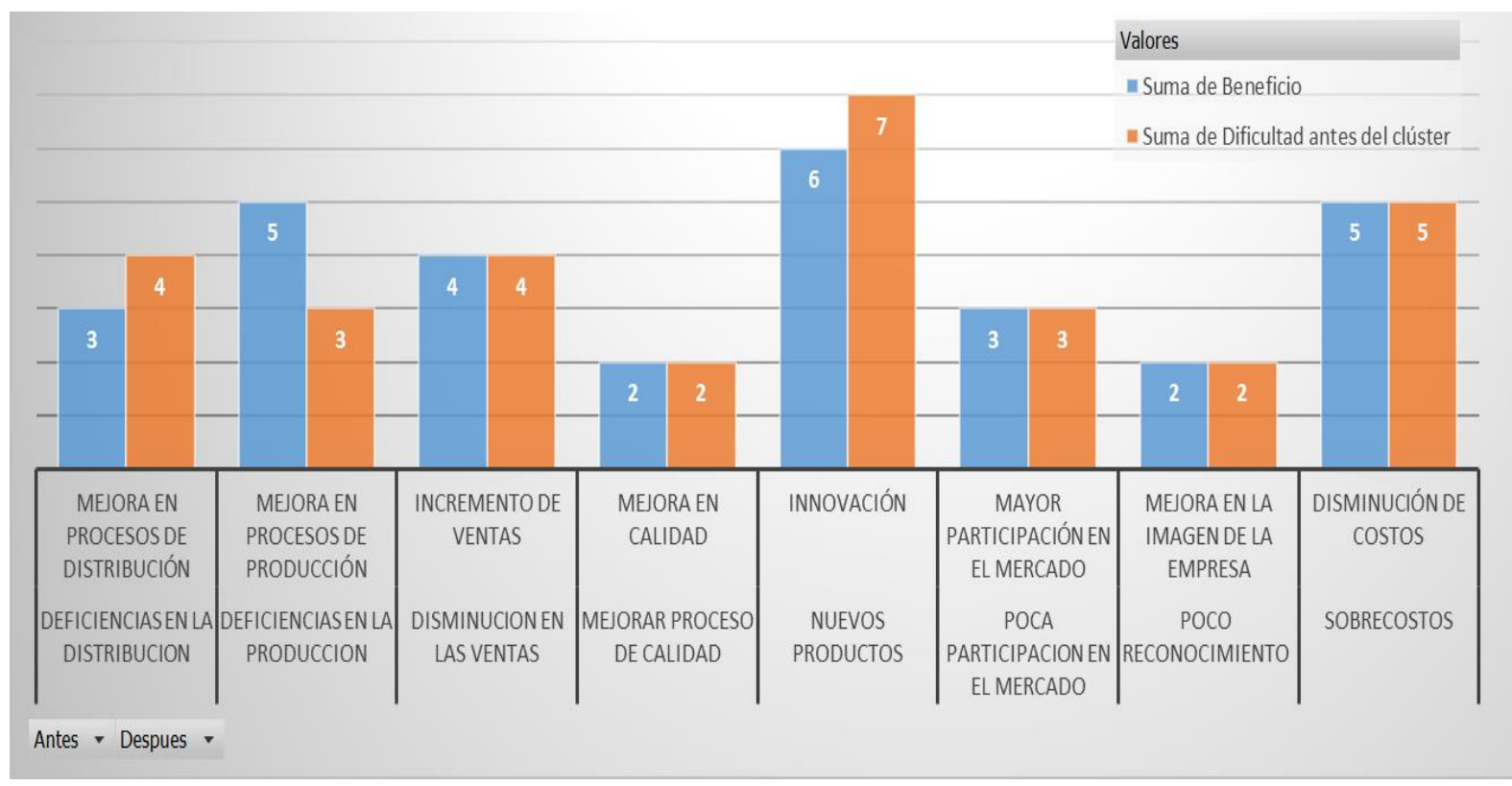

Grafica 9. Comparación grafica de las dificultades empresariales antes de pertenecer al clúster vs los beneficios obtenidos al ser integrante del clúster

El tercer objetivo busca comparar las empresas productoras que integran el clúster del sector del cuero, calzado y marroquinería en Bogotá a través de los años de participación en el clúster, para sugerir mejoras. Para mostrar los resultados para dar alcance a este objetivo se realiza la gráfica No. 10 la cual muestra el tiempo de 
permanencia de las empresas productoras que integran el clúster del sector del cuero, calzado y marroquinería en Bogotá.

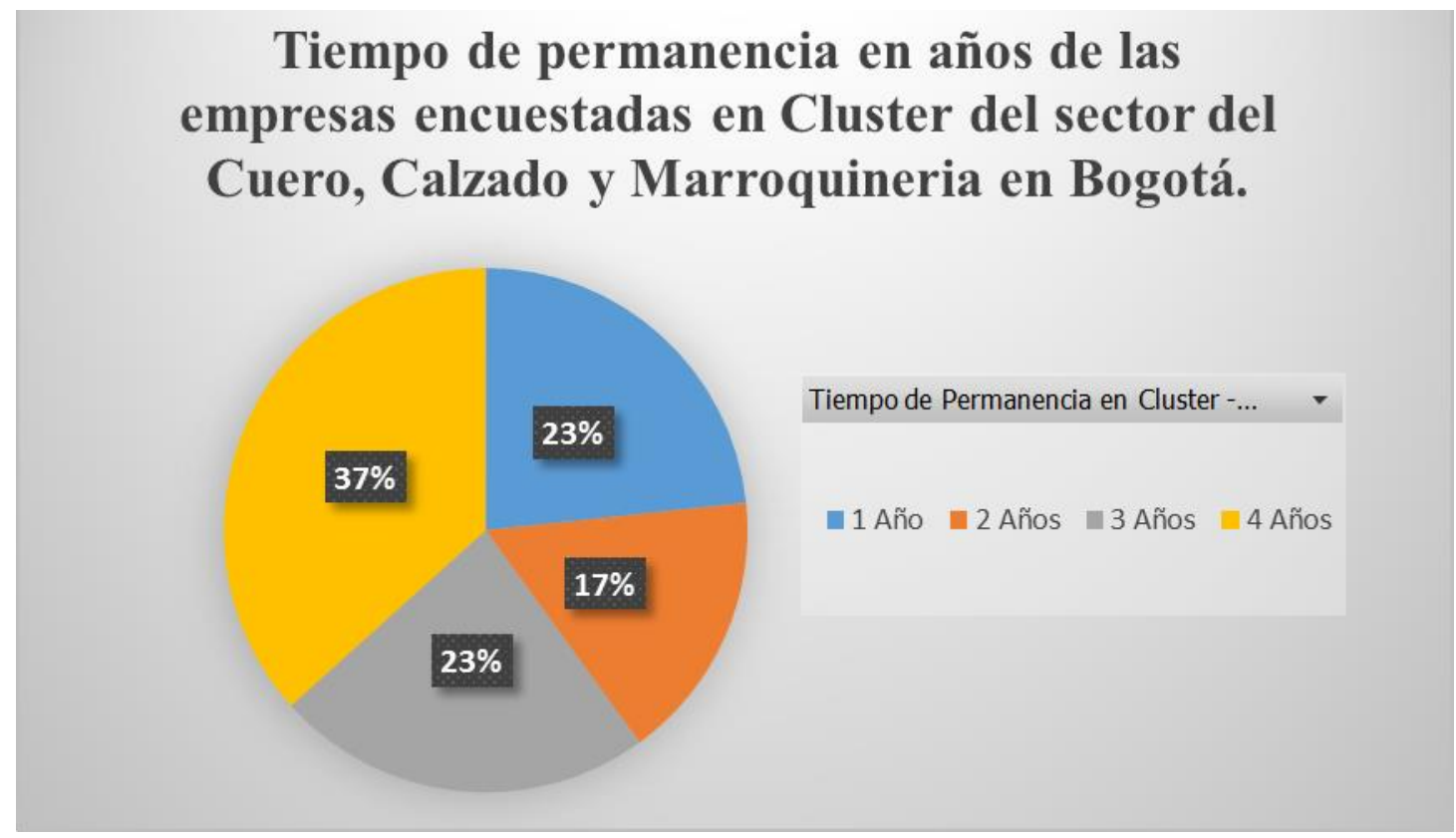

Grafica 10. Tiempo de permanencia de la muestra empresarial que está vinculada al clúster del sector del cuero, calzado y marroquinería en Bogotá.

Según lo anterior se obtiene los siguientes resultados:

$\checkmark$ De 30 empresas productoras encuestadas que integran el clúster, 7 tiene un año de participación, lo cual equivale al $23 \%$ del total.

$\checkmark$ De 30 empresas productoras encuestadas que integran el clúster, 5 tienen dos años de participación, lo cual equivale al $17 \%$ del total.

$\checkmark$ De 30 empresas productoras encuestadas que integran el clúster, 7 tienen tres años de participación, lo cual equivale al $23 \%$ del total.

$\checkmark$ De 30 empresas productoras encuestadas que integran el clúster, 11 tienen cuatro años de participación, lo cual equivale al $37 \%$ del total.

Por lo tanto, se logra observar que la concentración de las empresas integrantes son las de mayor antigüedad, por lo tanto, se puede inferir que la participación continua ha sido beneficiosa y productiva tanto para la empresa como para el sector. 
Teniendo en cuenta los resultados de la gráfica No.10 de la antigüedad de las empresas de la muestra, se realiza la comparación entre el tiempo de permanencia de las empresas productoras que integran el clúster del sector del cuero, calzado y marroquinería de Bogotá frente al beneficio obtenido. Esto con el fin de definir si según la antigüedad de empresa en el clúster se obtienen diferentes beneficios.

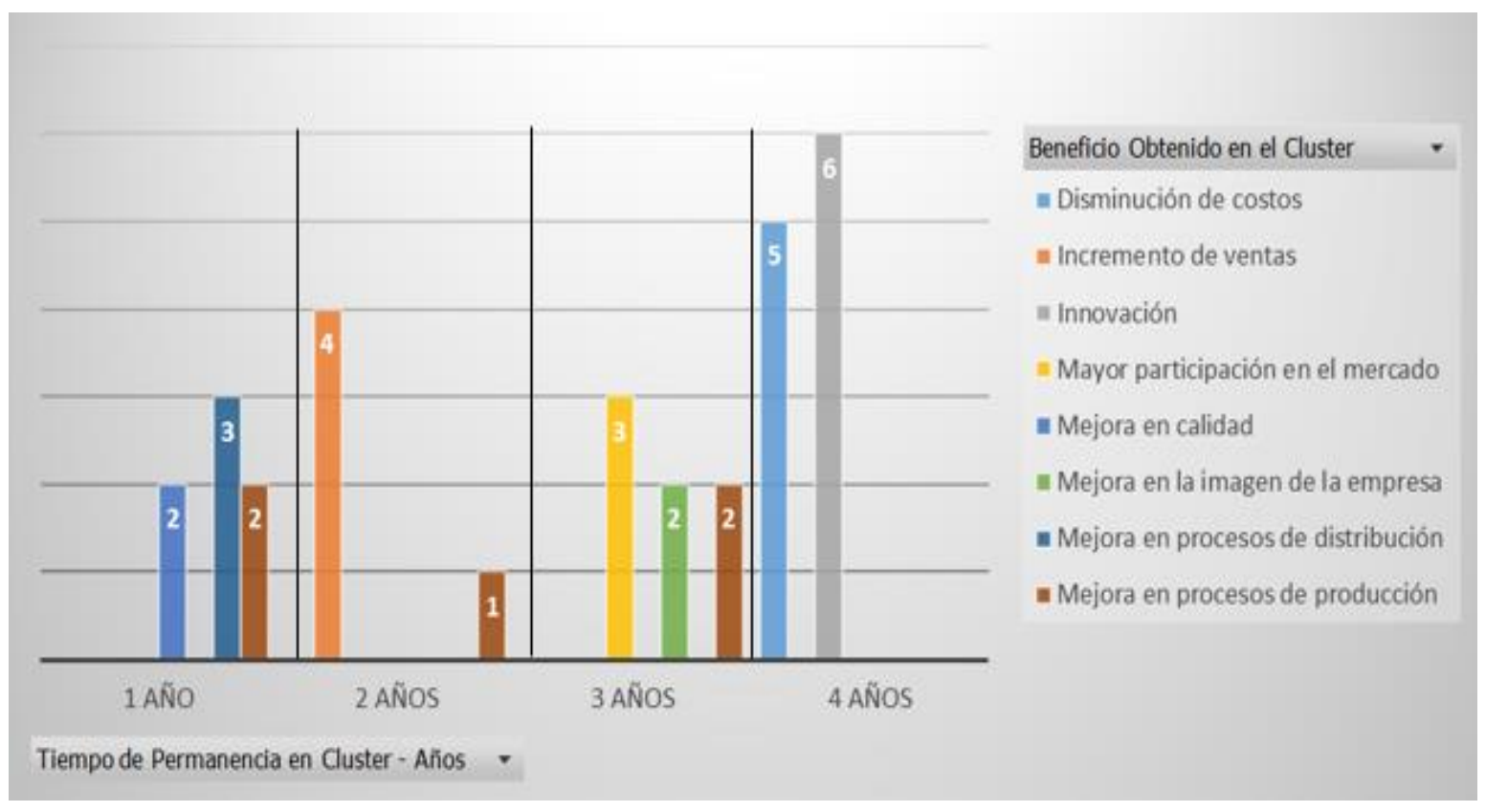

Grafica 11. Comparación de los beneficios recibidos por las empresas productoras del sector del cuero, calzado y marroquinería, teniendo en cuenta el tiempo de pertenencia.

La gráfica No.11 muestra la siguiente información:

$\checkmark$ Hay siete empresas que tienen antigüedad de un año, donde dos de ellas manifestaron mejoras en calidad, tres en procesos de distribución y dos en proceso de producción y estos beneficios en el primer año, esto se puede atribuir a las capacitaciones que realiza en el clúster por medio de las entidades de apoyo.

Hay cinco empresas que tienen antigüedad de dos años, donde cuatro de ellas manifestaron incremento de ventas y una mejora en su proceso de producción, estos beneficios se pueden atribuir a las redes y alianzas de los clústers, donde 
pueden obtener nuevos clientes y las capacitaciones de las entidades de apoyo para el mejoramiento de procesos.

Hay siete empresas que tienen antigüedad de tres años, donde tres de ellas manifestaron tener mayor reconocimiento en el mercado, dos con mejor imagen de la empresa y dos con mejores procesos de producción, y estos beneficios se pueden vincular con redes o alianzas donde se dan a conocer como empresa y las capacitaciones de las entidades de apoyo para el mejoramiento de procesos.

Hay 11 empresas que tienen antigüedad de cuatro años que algunas con las que inicio el clúster del sector del cuero, calzado y marroquinería en Bogotá, donde seis de ellas manifestaron obtener innovación en sus compañías, no solo en producto sino también en procesos, lo cual nace de un proceso largo de mejora e interacción entre empresas para crear e innovar en el mercado para mantenerlo activo y cinco obtuvieron disminución de costos donde se resalta a gran escala una integración de la empresa productora con su proveedor donde se logra la minimización de los costos y esto se debe a que el proveedor actúa como otro actor del clúster.

Teniendo en cuenta los resultados de la gráfica No.11 se realizan las siguientes sugerencias de mejora para el clúster del sector del cuero, calzado y marroquinería en Bogotá,

Uno de los aspectos más importantes en un clúster es la innovación, y según los resultados de la gráfica No 11 las empresas han innovado, pero son las que tienen la máxima antigüedad en el clúster que son cuatro años, por lo tanto, recomendamos crear necesidades que requieran una implementación de procesos o sistemas de innovación, para aumentar los servicios orientados a la creación y fortalecimiento de sus procesos de innovación. 
$\checkmark$ El mejoramiento continuo es muy importante, por lo tanto, se debe realizar un diagnóstico a las empresas que ingresan al clúster, dado que sugerimos que todos los actores que ingresen deben ser capacitados sobre clúster, y posteriormente capacitarlos sobre las dificultades que fueron identificadas en el diagnóstico, para que los beneficios se evidencien desde el primer año de permanencia en el clúster.

Según la gráfica No 11 existe dos beneficios que son la imagen de la empresa y posicionamiento en el mercado se debe fortalecer realizando alianzas con organizaciones, gremios u otros clústers que nos aporten visibilidad nacional e internacional para lograr un posicionamiento sumándole que puede ser un incremento de ventas en el caso de lograr exportaciones.

El último objetivo planteado en la investigación busca analizar la información recopilada a las empresas productoras y entidades de apoyo que integran el clúster del sector del cuero, calzado y marroquinería en Bogotá, para resaltar la importancia de integrar un clúster. Por lo tanto, este objetivo es resalta la importancia del clúster en las empresas productoras del sector del cuero, calzado y marroquinería de Bogotá, por lo cual a lo largo de la investigación se logra evidenciar la gran influencia e impacto que está causando y como el clúster se está volviendo tendencia en los diversos sectores económicos del país.

Para el caso del sector del cuero, calzado y marroquinería de Bogotá ha permitido que las empresas productoras mejoren e innoven toda su línea de productos logrando un incremento en sus ventas abarcando el mercado nacional, compitiendo con el mercado extranjero. Por otro lado, se logra evidenciar como a partir del trabajo colaborativo entre las empresas que integran el clúster de Bogotá han ayudado a suplir sus propias necesidades impulsando el crecimiento del sector y mejorando su competitividad.

A partir de la acogida que ha tenido el clúster en el sector del cuero, calzado y marroquinería en Bogotá, se ha empezado a trabajar de la mano de otras instituciones de 
apoyo con la formación y capacitación, para obtener mejores resultados y estándares de calidad. En la actualidad se estableció el convenio entre la Acicam y el SENA con una inversión de 13 mil millones de pesos destinados a la compra de maquinaria y tecnología con el fin de formar a más de 40 mil colombianos en programas técnicos, tecnólogos, operarios y auxiliares para el sector.

Como parte de la iniciativa clúster del sector en alianza con otros sectores económicos del país, surgió el proyecto para el abastecimiento de calzado para Clínicas y Hospitales, lo que permite el abastecimiento y posicionamiento del mercado nacional haciendo frente a la importación de producto extranjero.

Lo expuesto anteriormente ratifica la importancia del clúster del sector del cuero, calzado y marroquinería en Bogotá, ya que ha permitido generar cambios de valor para el crecimiento del sector guiado por el trabajo conjunto con el fin de generar beneficios comunes para el fortalecimiento competitivo de la empresa productora del sector. 


\section{Discusión de resultados}

Después de recopilar toda la información obtenida de las diferentes herramientas implementadas se segmento la información obtenida y se extrajo lo importante para poder demostrar los objetivos planteados al inicio de este trabajo de grado.

El primer objetivo específico que planteamos es identificar los beneficios de las empresas productoras que integran el clúster del sector del cuero, calzado y marroquinería en Bogotá, para evidenciar la situación de las empresas antes de integrar el clúster; este objetivo fue alcanzado, ya que la encuesta aplicada a las empresas seleccionadas como muestra arrojo resultados satisfactorios los cuales fueron contrastados con las teorías que se tuvieron en cuenta para la revisión documental.

De los resultados obtenidos se pudo evidenciar situaciones que presentan las empresas cuando enfrentan solas el mercado como disminución en ventas, sobrecostos, poca participación en el mercado, poca innovación por lo tanto un portafolio pobre y deficiencia en procesos de producción, distribución y calidad; estas dificultades llevo a las empresas a participar al clúster del sector del cuero, calzado y marroquinería en Bogotá donde con el pasar del tiempo se empezaron a observar una variedad de beneficios como:

\footnotetext{
Aumento en ventas

Disminución de costos

$\checkmark$ Reconocimiento en el mercado

$\checkmark$ Mejora en la imagen de la empresa

$\checkmark$ Mejora en el proceso de distribución

$\checkmark$ Mejora en el proceso de producción

$\checkmark$ Innovación

$\checkmark$ Mejora en procesos de calidad

$\checkmark$ Productividad
} 
Estos que son los beneficios obtenidos comprueban la Teoría Geográfica Económica de Paul Krugman y de la competitividad de Michael Porter, ya que ambas teorías dicen que la unión de empresas del mismo sector y que integren la cadena productiva se obtienen beneficios como mejora en procesos de producción y distribución, optimización de costos y aumento de productividad.

El segundo objetivo planteado es contrastar los beneficios obtenidos por las empresas que integran el clúster del sector del cuero, calzado y marroquinería en Bogotá, frente a las necesidades organizacionales antes de integrar el clúster, para demostrar el indicador de cumplimiento del clúster. Este objetivo fue logrado, ya que por medio de la información obtenida de las encuestas se pudo determinar que las dificultades que presentaban las empresas en su mayoría durante la participación en clúster fueron superadas, arrojando los siguientes indicadores:

$\checkmark$ Cinco de las dificultades fueron superada en un $100 \%$

$\checkmark$ Una de las dificultades fue superada por el $167 \%$

$\checkmark$ Dos de las dificultades no fueron superadas en su totalidad, pero cabe resaltar que se su porcentaje de cumplimiento supera el $50 \%$

Según lo anterior se logra afirmar que los beneficios del clúster se alcanzan por medio de la colaboración entre sus integrantes, ya que el problema particular de una empresa se convierte en colectivo y la solución es busca entre todos los actores que integran el clúster como lo expreso el Doctor Juan Diego el Director de la Iniciativa Clúster del sector del cuero, calzado y marroquinería en Bogotá dirigido por la Cámara de Comercio de Bogotá.

Adicional, se encuentra como a partir de una dificultad en las empresas se genera el interés de participar de un clúster en pro de tomar mejores decisiones que permitan el crecimiento en diversos factores. También se logra evidenciar que la mayoría de las empresas superan su problemática inicial, sin embargo, dado el caso de que no hayan logrado superar este han obtenido otros beneficios. 
El tercer objetivo que se planteó es comparar las empresas productoras que integran el clúster del sector del cuero, calzado y marroquinería en Bogotá a través de los años de participación en el clúster, para sugerir mejoras al clúster. Cuando se realizaron las encuestas se solicitó una información adicional, donde se encontró que las empresas que están en clúster desde sus inicios han obtenidos mayores beneficios, pero también se pudo evidenciar que no existe un orden en los beneficios según la antigüedad, dado que cuando las empresas ingresan al clúster empiezan a participar en todos los proyectos sin tener en cuenta sus necesidades por lo tanto en algunas empresas mencionaron no solucionar sus problemáticas por la falta de organización, por esta razón, se realizan las siguientes sugerencias de mejora,

$\checkmark$ El mejoramiento continuo es muy importante, por lo tanto, se debe realizar un diagnóstico a las empresas que ingresan al clúster, dado que sugerimos que todos los actores que ingresen deben ser capacitados sobre clúster, y posteriormente capacitarlos sobre las dificultades que fueron identificadas en el diagnóstico, para que los beneficios se evidencien desde el primer año de permanencia en el clúster.

Uno de los aspectos más importantes en un clúster es la innovación, pero las empresas que mencionan que obtuvieron este beneficio son las que tienen la máxima antigüedad en el clúster que son cuatro años, por lo tanto, recomendamos crear necesidades que requieran una implementación de procesos o sistemas de innovación, para aumentar los servicios orientados a la creación y fortalecimiento de sus procesos de innovación.

Existen dos beneficios que son la imagen de la empresa y posicionamiento en el mercado, los cuales se deben fortalecer realizando alianzas con organizaciones, gremios u otros clústers que aporten visibilidad nacional e internacional para lograr un posicionamiento sumándole que puede ser un incremento de ventas en el caso de lograr exportaciones, que es una de las 
oportunidades que brinda la teoría de valor compartido de Michael Porter la "Reinvención de productos y mercados".

El cuarto y último objetivo es analizar la información recopilada a las empresas productoras y entidades de apoyo que integran el clúster del sector del cuero, calzado y marroquinería en Bogotá, para resaltar la importancia de integrar un clúster. Para dar respuesta a este objetivo se combinaron las cuatro herramientas que se describieron en el modelo metodológico donde se puede concluir que un clúster es una herramienta que brinda crecimiento económico, al tiempo genera un sin número de beneficios que se han venido nombrando a lo largo del trabajo y donde logra evidenciar que hacer parte de clúster es de grande importancia, como se dio a conocer por medio de la entrevista las empresas son el único ente generador de empleo por lo tanto de sostenibilidad económica para sociedad, por lo tanto es importante que las empresas sean responsables y al tiempo busque ampliar sus horizontes en temas de competitividad y valor compartido como lo menciona Michael Porter en estas dos teorías que buscar generar productividad, incrementar la innovación y fomentar la creación de empresas partiendo de reinventar los mercados y productos, redefinir e unir la cadena productiva y desarrollo de las empresas.

Por lo tanto, un clúster es una herramienta que hoy en día puede ayudar a fomentar el crecimiento económico y social para lograr desarrollo empresarial que lleva a concluir que un clúster bien conformado es un generador de proyectos que beneficia a los diferentes sectores productivos y en este caso al sector del cuero, calzado y marroquinería en Bogotá que está unido por formar una sola cadena productiva en este caso la del cuero.

Teniendo en cuenta lo anterior se determina que la importancia de integrar un clúster es buscar el beneficio común para el crecimiento sostenido de la sociedad. 


\section{Conclusiones}

De acuerdo al análisis realizado a las empresas productoras y las entidades de apoyo que conforman el clúster del sector del cuero, calzado y marroquinería en Bogotá a través de la metodología de investigación planteada, permite establecer las siguientes conclusiones:

Todas las empresas obtienen beneficios, pero estos se alcanzan por medio de la interacción de los diferentes actores que conforman el clúster, por medio de las mesas de trabajo, que es el ámbito donde todos colaboran entre sí y plantean diferentes soluciones que enriquecen los diferentes procesos productivos del sector.

Los beneficios que las empresas obtienen al ser integrante del clúster impactan directamente en el desempeño de las compañías, y por lo tanto a su competitividad, productividad e innovación y estar una constante reinvención y redefinición de estos para enfrentar los cambios del mercado.

$\checkmark$ Todos los beneficios alcanzados por las empresas, en donde algunos son de mayor importancia que otros, esto tiene que ver con el impacto de las mejoras en las áreas intervenidas y tiempo de la implementación de las mejoras, por esta razón las empresas con mayor antigüedad han obtenido más beneficios y han logrado una mejor integración de la cadena productiva del sector del cuero, calzado y marroquinería que es solo una basada en la extracción y trasformación del cuero.

$\checkmark$ En la presente investigación las empresas reportaron disminución en costos y aumento en ventas, estos beneficios los pudieron evidenciar con mejoras en la reducción de costos operativos o tiempos y además del crecimiento que algunas empresas han tenido por el incremento en ventas que las han vuelto más competitivas. 
$\checkmark$ Las empresas valoran participar en el clúster, aunque los beneficios no los cuantifiquen, el impacto cualitativo puede obtener lo valoran ya lo ven como un fortalecimiento social, económico, político de manera participativo y colaborativo para el mejoramiento de la sociedad. 


\section{Recomendaciones}

En este proyecto de grado se evidencia como el clúster ha influenciado de manera positiva a las empresas que hoy en día lo conforman, sin embargo, en la aplicación de las encuestas a estas empresas productoras se logra recoger información adicional lo que nos permite como estudiantes de administración de empresas establecer sugerencias de mejora para la obtención de mayores resultados de los beneficios que ofrece el clúster del sector del cuero, calzado y marroquinería en Bogotá.

Durante la investigación de campo se observa como las empresas han obtenido mejores resultados en diferentes áreas de la organización, sin embargo, en revisiones periódicas se evidencia que aun presentan la falencia inicial con la cual se integraron a clúster, por lo cual se sugiere:

La primera recomendación para las empresas productoras del clúster del sector del cuero, calzado y marroquinería en Bogotá es realizar un diagnóstico de su situación como empresa, hacer una revisión interna de cuáles son las falencias presentadas que obstaculizan su crecimiento, todo esto antes de integrar el clúster, esto con el fin de identificar cuales sus necesidades primordiales y atacarlas con las ayudas ofrecidas por las alianzas que integran el clúster.

Otra situación evidenciada en campo, está en los pocos canales de comunicación que hay entre las entidades de apoyo y las empresas productoras del sector. De acuerdo a entrevista con Juan Diego Cardona Director del clúster del sector del cuero, calzado y marroquinería de Bogotá, comenta acerca del crecimiento del mismo pero su participación no llega al cien por ciento de las empresas debido al tiempo de cada uno de los representantes de las empresas y al desconocimiento de cómo funciona el clúster.

De acuerdo a lo anterior se da una segunda recomendación con respecto a la comunicación empleada ya que no es la más efectiva, por lo cual se sugiere hacer uso de las redes sociales además realizar capacitaciones a las empresas en el momento que 
integran y son nuevos en el clúster, para conocer cómo funciona, cuáles son sus actores, como intervenir y hacer uso de los recursos que ofrecen las entidades de apoyo y así poder sacar el mayor provecho a cada una de las reuniones entre los diferentes actores y ser partícipes de las capacitaciones ofrecidas para el crecimiento y desarrollo organizacional. 


\section{Referencias}

Alvarez, A. (2004). Universidad de Palermo. Obtenido de http://fido.palermo.edu/servicios_dyc/blog/images/trabajos/6750_22004.pdf

Andrade, D. (2016). Pontifica Universidad Catolica del Ecuador. Obtenido de Economía y Finanzas Internaciones : http://www.puce.edu.ec/economia/efi/index.php/economiainternacional/15-progresos/51-nueva-geografia-economica

Baena, G. (2009). Investigaciòn Estrategica . Barranquilla: De Marketing de Colombia .

Becattini, G. (2002). Del distrito industrial marshalliano a la «teoría del distrito» contemporánea. Madrid: Asociación Española de Ciencia Regional.

Botero, L. G. (03 de Agosto de 2015). Crisis en la industria del calzado en Bogotá. Las 2 Orillas.

Camara de Comercio de Bogotá. (2012). Camara de Comercio de Bogotá. Obtenido de Camara de Comercio de Bogotá: http://www.ccb.org.co/Fortalezca-su-empresa/Iniciativas-dedesarrollo-de-Clusters

Camara de Comercio de Bogotá. (Octubre de 2014). Camara de Comercio de Bogotá. Obtenido de Camara de Comercio de Bogotá: http://www.ccb.org.co/Sala-de-prensa/NoticiasCCB/2014/Octubre/Las-Iniciativas-de-Desarrollo-Cluster-estrategias-para-el-crecimiento

Camara de Comercio de Madellin. (2015). Camara de Comercio de Madellin. Obtenido de Camara de Comercio de Madellin: http://www.camaramedellin.com.co/site/Cluster-yCompetitividad/Comunidad-Cluster.aspx

Cluster Bogotá Cuero, Calzado y Marroquinería. (2012). Cluster Bogotá Cuero, Calzado y Marroquinería. Obtenido de Cluster Bogotá Cuero, Calzado y Marroquinería: http://www.ccb.org.co/Clusters/Cluster-de-Cuero-Calzado-y-Marroquineria/Directorio

Crouch, C., \& Farell, H. (2001). Great Britain: Falling through the holes in the network concept. Oxford University Press, Oxford.

Departamento Nacional de Planeación. (2004). Cuero, Calzado e Industria de Marroquineria . Obtenido de Departamento Nacional de Planeación: https://colaboracion.dnp.gov.co/CDT/Desarrollo\%20Empresarial/Cueros.pdf

Feed Back Networks. (2013). Feed Back Networks. Obtenido de Calculo de la Muestra : http://www.feedbacknetworks.com/cas/experiencia/sol-preguntar-calcular.html

Feser, E. (1998). Viejas y nuevas teorías de grupos de la industria. Clusters y especialización regional: En Geografía, Tecnología y Redes. Chapel Hill: Universidad de Carolina del Norte.

Flórez, L. G. (2 de Febrero de 2011). La crisis del cuero. (Espectador, Entrevistador) 
Flórez, L. G. (19 de Enero de 2015). La Industria del cuero está en crisis. (L. G. Rogriguez, Entrevistador)

Hernández Sampieri, R., Fernández Collado, C., \& Baptista Lucio, M. (2010). Metodologia de la Investigación. Quinta Edición. Mexico: McGRAW-HILL / INTERAMERICANA EDITORES, S.A. DE C.V.

Kramer, M., \& Porter, M. (2011). Creando Valor Compartido. Harvard Business Review.

Plan de negocios del Sector de Cuero, Calzado y Marroquineria. (2013). Plan de negocios del Sector de Cuero, Calzado y Marroquinería: Una respuesta para la transformación productiva. Bogota.

Porter, M. (1991). La Ventaja Ccompetitiva de las Naciones. Harvard Business School Press.

Porter, M. (1998). On competition. Harvard Business School Press.

Porter, M. (2009). Ser Competitivo. Barcelona: Ediciones Deusto.

Red Cluster Colombia. (Junio de 2016). Red Cluster Colombia. Obtenido de Red Cluster Colombia: http://redclustercolombia.com/noticias/entradas/bienvenidos-a-la-red-clustercolombia/50

Reina, G. D. (2015). Bondades de la estrategia clúster para el desarrollo regional. Revista Nova et Vetera.

Roelandt, T., \& Den Hertog , P. (1999). El análisis de conglomerados y la formulación de políticas basadas en clúster en los países de la OCDE: una introducción al tema. Paris: OCDE.

Rosenfeld, S. (1997). Bringing business clusters into the mainstream of economic. European Planning Studies.

Simmie, J., \& Sennett, J. (2002). Innovación y Clustering en la Región Metropolitana de Londres. Oxford Brookes School of Planning .

Tamayo, M. T. (2004). El proceso de la investigación científica. Mexico: Limusa. 


\section{Anexos \\ Anexo No. 1 - Entrevista a Doctor Juan Diego Cardona Echeverry}

El 18 de octubre del 2016 nos reunimos a las 8 am en las instalaciones de Cámara

de Comercio de Bogotá - Sede Salitre con el Doctor Juan Diego Cardona Echeverry Director de la Iniciativa Clúster sector del cuero, calzado y marroquinería. Donde realizamos una entrevista donde el objetivo general era identificar las diferentes ventajas y desventajas de esta iniciativa.

\section{Transcripción de la entrevista:}

Entrevistador: Buenos días, primero que todo nos presentamos soy Yeraldin Bernal y Michael Quevedo, nosotros somos estudiantes de la Universidad Santo Tomás de último semestre, actualmente nos encontramos desarrollando nuestro proyecto de grado modalidad Monografía la cual esta titulada "Clúster, estrategia del sector del cuero, calzado y marroquinería en Bogotá", la cual está enfocada a investigar como un clúster puede contribuir al crecimiento del sector del cuero, calzado y marroquinería y cuáles son los factores claves para lograr un crecimiento.

Doc. Juan Diego: Buenos días Yeraldin y Michael, soy el Director de la Iniciativa Clúster del sector del cuero, calzado y marroquinería, esta iniciativa la dirijo desde que nació en el año 2012. ¿Porque la dirijo se preguntarán? Siempre estado vinculado a este sector por medio de Centro Tecnológico Para Las Industrias Del Calzado Cuero y Afines, Programa de Diseño y Desarrollo de Productos del Calzado y Cuero y Miembro de Comité Técnico en el Sena Centro de Manufactura Textil y Del Cuero. Mi experiencia me ha brindado la oportunidad de conocer el sector y poder ahora liderar este proyecto con la Cámara de Comercio.

Entrevistador: Primera pregunta es ¿Qué es un clúster y una iniciativa clúster? y ¿Cuál es su diferencia? 
Doc. Juan Diego: Un clúster en terminología muy de Harvard es una concentración de actores con interés económico en un mismo sector geográfico. Y por otro lado una iniciativa clúster es un proyecto que buscar integrar diferentes actores de la sociedad como empresas, gobierno, entidades de apoyo y la academia para que el clúster desarrolle competitividad y valor compartido. Por lo tanto, su diferencia está en que el clúster se puede estancar, pero la iniciativa siempre va busca una forma de genera valor compartido e impulsar el crecimiento y competitividad.

Entrevistador: ¿Cuál es el objetivo de la Cámara de Comercio de Bogotá en para promover la Iniciativa Clúster del sector del cuero, calzado y marroquinería?

Doc. Juan Diego: Propósito de $\mathrm{CCB}$ es impulsar el desarrollo competitivo en generar prosperidad "Un tejido empresarial" en dos líneas competitividad y valor compartido.

Entrevistador: ¿Cómo funciona el clúster del sector del cuero, calzado y marroquinería?

Doc. Juan Diego: Los clústeres pueden funcionar de dos formas, primera que no pase nada y el clúster siga un funcionamiento estable y con tiempo desaparezca o crezca, pero sin impacto alguno o segunda, se interviene el clúster para generar que sucedan cambios y eso es lo que se llama iniciativa clúster.

En especial este sector tiene un clúster de empresas fabricantes donde curten pieles y fabrican calzado hace más de 100 años, por lo tanto, la cámara de comercio lo que hace interviene el clúster para mejorar la competitividad y generar prosperidad, ya que el único generador valor económico es la empresa, por lo tanto, se busca fortalecer las empresas para que generen empleo como ejemplo.

Entrevistador: ¿Qué estrategias ha implementado la CCB para intervenir el clúster?

Doc. Juan Diego: La cámara tiene unos procesos metodológicos, pero es importante aclarar que no es CCB la que decide, sino son los diferentes actores del clúster que son las empresas, entidades de gobierno, la academia, los gremios, entre otros. La CCB pone 
a disposición del clúster la secretaria técnica, lo que se hace es impulsar encuentros para que se establezcan líneas de acción, definir intereses y hacia donde se quiere llevar la industria.

Existen áreas de intervención que buscan definir que se requiere para que pase, y tiene dos aspectos de intervención:

1. Intervenir el interior de la empresa, con el fin mejorar sus procesos, su posición competitiva, sea efectiva.

2. Entorno de la empresa, como esta en el aspecto político, académico, legal, medio ambiente.

Esta es la manera que CCB interviene en el clúster y en sus nuevos integrantes. Secretaria técnica busca es construir acuerdos para crecimiento e interés colectivo y colaborativo. Por lo tanto, si se identifican problemas se buscan las soluciones con los diferentes actores en el comité ejecutivo que está conformado por las empresas y mesas de trabajo.

Entrevistador: ¿Cómo se invitan a las empresas hacer parte de la iniciativa clúster?

Doc. Juan Diego: Son varios momentos, el primero momento es cuando se inicia identificando los actores claves como empresarios líderes, empresas de impacto y entidades de apoyo, y se realiza una aproximación lideres donde se indaga si ven viable la iniciativa. Luego, se empieza por medio de estos actores a identificar más empresas.

El segundo momento es cuando ya existen proyectos andando y se empieza a vincular más empresas, por ejemplo, programas de financiamiento, por lo tanto, se empiezan a vincular los bancos como actores de la iniciativa.

Entrevistador: ¿Las empresas que se vinculan requieren un musculo financiero?

Doc. Juan Diego: No se requiere musculo financiero, ya que es un tema de pensamiento colectivo. Lo más importante para hacer parte de una iniciativa es disposición de tiempo para las reuniones de una vez al mes para discutir temas del sector.

Entrevistador: ¿Cuál es el papel de la academia al vincularse a una iniciativa clúster? 
Doc. Juan Diego: Es muy importante el apoyo de la academia, ya que ayuda a desarrollar nuevos conocimientos, cursos de capacitación, de hecho, actualmente tenemos dos universidades vinculadas a esta iniciativa lo cual ha sido constructivo para el clúster.

Entrevistador: Para terminar, queremos agradecer que nos haya concedido esta entrevista. 


\section{Anexo No. 2 - Modelo de la Encuesta Aplicada}

ENCUESTA CLÚSTER DEL SECTOR DEL CUERO, CALZADO Y MARROQUINERÍA EN BOGOTÁ.

Fecha de Aplicación:

Nombre Empresas:

Nombre de quién contesta:

Antigüedad en clúster:

1. ¿La empresa ha asistido a una capacitación sobre clúster?

\section{$\mathrm{Si}$}

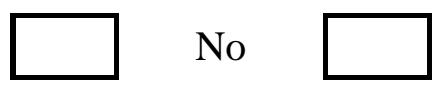

2. ¿Ha sido útil para la empresa participar del clúster del sector del Cuero, Calzado y Marroquinería?

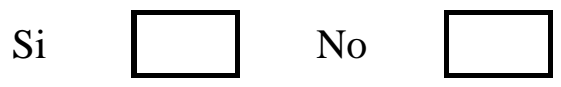

3. ¿La empresa ha recibido asesoría de alguna entidad de apoyo que pertenezca al clúster del sector del Cuero, Calzado y Marroquinería?

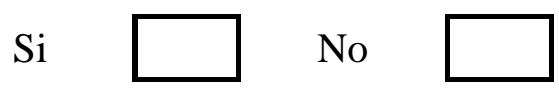

4. ¿Cómo la empresa conoció el clúster del sector del Cuero, Calzado y Marroquinería?

\begin{tabular}{|l|l|}
\hline Cámara de Comercio Bogotá & \\
\hline Internet & \\
\hline Empresas vinculadas al clúster & \\
\hline Campañas de entidades de apoyo & \\
\hline Otros & \\
\hline
\end{tabular}

5. Califique el clúster del sector del Cuero, Calzado y Marroquinería en Bogotá

\begin{tabular}{|l|l|}
\hline Excelente & \\
\hline Sobresaliente & \\
\hline Buena & \\
\hline Regular & \\
\hline Mala & \\
\hline
\end{tabular}


6. ¿Con que tipo de empresas ha tenido mayor relación en clúster del sector del cuero, calzado y marroquinería?

\begin{tabular}{|l|l|}
\hline Proveedores & \\
\hline Distribuidores & \\
\hline Clientes & \\
\hline Competidores & \\
\hline Centros de Educación & \\
\hline
\end{tabular}

7. ¿Qué beneficio ha obtenido la empresa con el clúster del sector del Cuero, Calzado y Marroquinería?

\begin{tabular}{|l|l|}
\hline Incremento de ventas & \\
\hline Disminución de costos & \\
\hline Mayor participación en el mercado & \\
\hline Mejora en la imagen de la empresa & \\
\hline Mejora en procesos de producción & \\
\hline Mejora en procesos de distribución & \\
\hline Innovación & \\
\hline Mejora en calidad & \\
\hline
\end{tabular}

8. ¿Que lo llevo a integrarse al clúster del sector del Cuero, Calzado y Marroquinería?

\begin{tabular}{|l|l|}
\hline Disminución en las ventas & \\
\hline Sobrecostos & \\
\hline Poca participación en el mercado & \\
\hline Poco reconocimiento & \\
\hline Deficiencias en la producción & \\
\hline Deficiencias en la distribución & \\
\hline Nuevos productos & \\
\hline Mejorar proceso de calidad & \\
\hline
\end{tabular}

